\title{
Genomic Survey of Candidate Stress-Response Genes in the Estuarine Anemone Nematostella vectensis
}

\author{
ADAM M. REITZEL ${ }^{1, *}$, JAMES C. SULLIVAN ${ }^{2, *}$, NIKKI TRAYLOR-KNOWLES ${ }^{2, *}$, \\ AND JOHN R. FINNERTY ${ }^{2, \dagger}$ \\ ${ }^{1}$ Biology Department, Woods Hole Oceanographic Institution, Woods Hole, Massachusetts 02543; and \\ ${ }^{2}$ Department of Biology, Boston University, 5 Cummington Street, Boston, Massachusetts 02215
}

\begin{abstract}
Salt marshes are challenging habitats due to natural variability in key environmental parameters including temperature, salinity, ultraviolet light, oxygen, sulfides, and reactive oxygen species. Compounding this natural variation, salt marshes are often heavily impacted by anthropogenic insults including eutrophication, toxic contamination, and coastal development that alter tidal and freshwater inputs. Commensurate with this environmental variability, estuarine animals generally exhibit broader physiological tolerances than freshwater, marine, or terrestrial species. One factor that determines an organism's physiological tolerance is its ability to upregulate "stressresponse genes" in reaction to particular stressors. Comparative studies on diverse organisms have identified a number of evolutionarily conserved genes involved in responding to abiotic and biotic stressors. We used homologybased scans to survey the sequenced genome of Nematostella vectensis, the starlet sea anemone, an estuarine specialist, to identify genes involved in the response to three kinds of insult-physiochemical insults, pathogens, and injury. Many components of the stress-response networks identified in triploblastic animals have clear orthologs in the sea anemone, meaning that they must predate the cnidariantriploblast split (e.g., xenobiotic receptors, biotransformative genes, ATP-dependent transporters, and genes involved in responding to reactive oxygen species, toxic metals, osmotic shock, thermal stress, pathogen exposure, and wounding). However, in some instances, stress-response genes known from triploblasts appear to be absent from the
\end{abstract}

Received 13 November 2007; accepted 14 February 2008.

* These authors contributed equally to this work.

† To whom correspondence should be addressed. E-mail: jrf3@bu.edu

Abbreviations: ECM, extracellular matrix; EST, expressed sequence tag; ROS, reactive oxygen species.
Nematostella genome (e.g., many metal-complexing genes). This is the first comprehensive examination of the genomic stress-response repertoire of an estuarine animal and a member of the phylum Cnidaria. The molecular markers of stress response identified in Nematostella may prove useful in monitoring estuary health and evaluating coastal conservation efforts. These data may also inform conservation efforts on other cnidarians, such as the reef-building corals.

\section{Introduction}

To survive and reproduce, organisms must deploy an array of molecular, physiological, and behavioral responses to avoid or counteract detrimental environmental conditions. These responses to environmental stress are often complex, involving many genes and integrating events at cellular and organismal levels. Except in cases where it is possible to simply flee stressful environmental conditions, an organism's response to most environmental stressorsboth natural and anthropogenic stressors-will typically involve changes in baseline gene expression that alter physiology, development, or behavior. Therefore, to study organismal stress responses, we must integrate environmental data, gene expression data, and organismal data (Ankley et al., 2006; Lee and Mitchell-Olds, 2006). The ongoing proliferation of genomic data is enabling comparative stressresponse studies on a phylogenetically wider sampling of taxa occupying a broader range of habitat types (Lettieri, 2006). It is now possible to compare evolved differences between species occupying diverse environments at both shallow and deep evolutionary divergences.

Nematostella vectensis as an estuarine sentinel species

Nematostella vectensis Stephenson, the starlet sea anemone, is one of the relatively small number of macroscopic 
animals that are year-round residents in estuarine environments. It is a small infaunal anemone (typically $<1 \mathrm{~cm}$ ) inhabiting salt marshes, saline lagoons, and other sheltered brackish environments. The species' range includes the eastern Pacific, western Atlantic, northern English Channel, and western North Sea (Hand and Uhlinger, 1994).

In recent years, Nematostella has emerged as a model system for developmental (Finnerty et al., 2004; Matus et al., 2006) and genomic studies (Sullivan et al., 2006; Putnam et al., 2007), and it has proven particularly informative for reconstructing the functional evolution of developmental regulatory genes whose origins can be traced to the cnidarian-triploblast common ancestor. It is useful for such studies because (1) it is an outgroup to the superphylum Triploblastica (=Bilateria; Fig. 1), (2) it is easy to culture in the laboratory through its entire sexual and asexual life history, and (3) its genome appears to have evolved in a relatively conservative fashion. A general finding of comparative genomic studies involving Nematostella is that the sea anemone exhibits remarkable genomic complexity and a surprising degree of genomic conservation relative to vertebrates, despite its extreme evolutionary distance from vertebrates (Technau et al., 2005; Sullivan et al., 2006; Putnam et al., 2007; Sullivan and Finnerty, 2007).

Nematostella is also useful for studying organismal responses to environmental stress because, in addition to extensive genomic resources, (1) it lives in a spatially and temporally variable habitat that is easily accessible, (2) it is easily subjected to laboratory stress studies, and (3) it is widely distributed (Hand and Uhlinger, 1994). Importantly, Nematostella has been collected in both pristine and anthropogenically impacted, degraded salt marsh habitats (Harter and Matthews, 2005), so it must be tolerant of a wide range of natural and anthropogenic stressors.

A first step in understanding how organisms sense and respond to stressors from the environment is to identify the genetic components of stress-response pathways. In this study, we searched the Nematostella genome to identify homologs of proteins known to be involved in sensing stress, counteracting particular stressors, and repairing damaged tissue. We divided the stress-response genes into three broad functional categories: (1) those that mediate chemical stresses, (2) those that counteract pathogens, (3) and those that underlie wound healing.

\section{Materials and Methods}

\section{Identifying proteins implicated in stress response in other taxa}

We compiled a list of proteins known to be involved in (1) chemical stress response, (2) innate immunity, and (3) wound healing. To identify genes involved in chemical stress response, we utilized a collection of "defensome" motifs compiled by Goldstone et al. (2006), with the following additions: zinc transporter (Pfam identifier PF02535); Ctr copper transporter family (PF04145); Cation efflux family (PF01545). To identify candidate genes involved in pathogen defense, we consulted the Innate Immu-

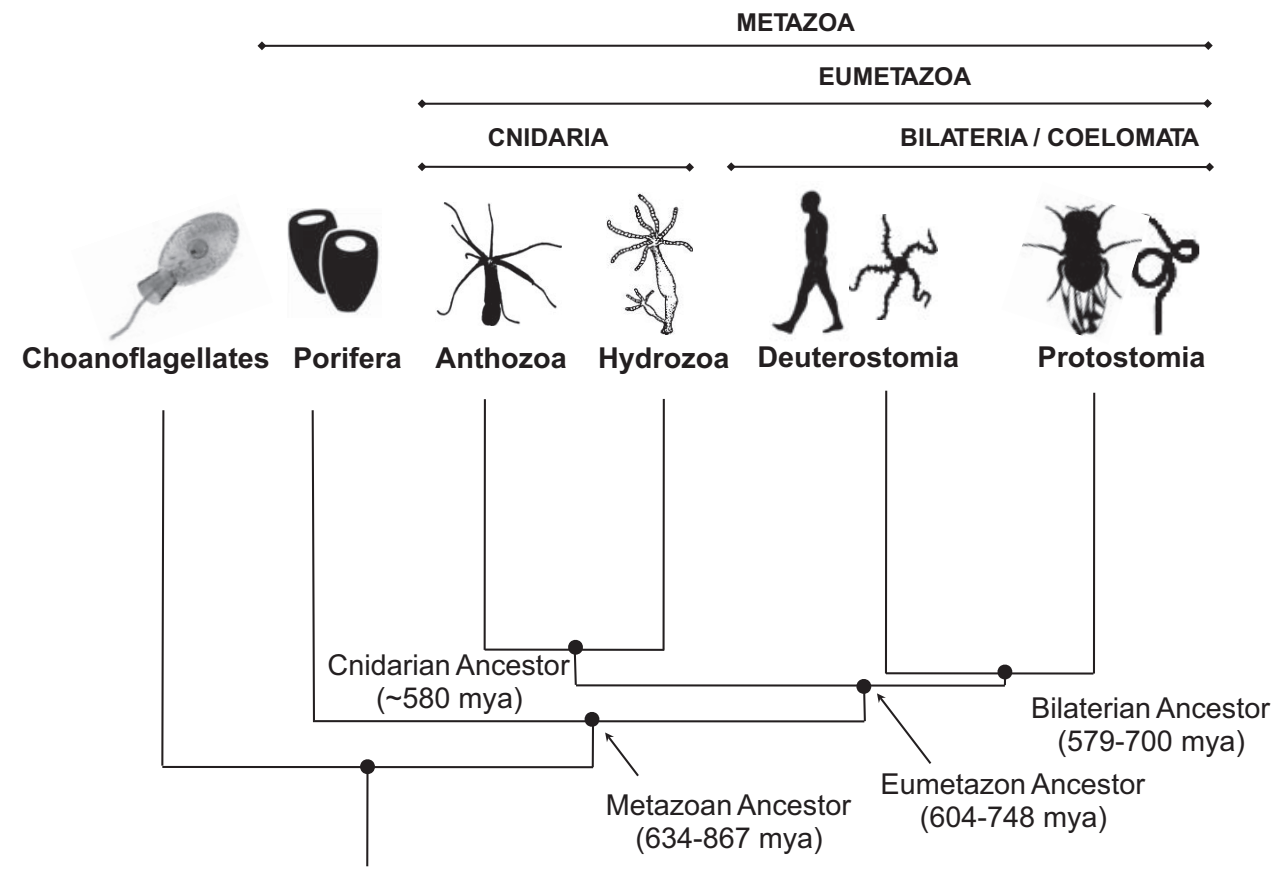

Figure 1. Metazoan phylogeny. The Cnidaria are the likely sister to the Bilateria (= Triploblastica). Dates for labeled ancestors are compiled from a number of sources (Aris-Brosou and Yang, 2002; Peterson et al., 2004; Peterson and Butterfield, 2005). 
nity Phylogenomic Explorer, ver. 2.0 (Krishnamurthy et al., 2006). We first eliminated those protein families whose functional connection to innate immunity is relatively tenuous-i.e., proteins annotated as "related to" innate immunity or that might "putatively" play a role in innate immunity. This left 128 protein families to which we could ascribe a role in innate immunity with higher confidence. To identify candidate genes involved in wound healing, we culled the recent literature on wound healing and regeneration (Kiritsy et al., 1993; Galko and Krasnow, 2004; Alvarado and Tsonis, 2006; Huxley-Jones et al., 2007).

\section{Identifying homologous proteins in Nematostella}

After assembling a list of stress-response query genes from other taxa (Fig. 2a), we sought to identify putative homologs in Nematostella. Our principal search strategy utilized conserved protein domains cataloged in the Pfam database, release 17 (Finn et al., 2006). For innate immune genes and chemical defense genes, lists of conserved Pfam domains had already been compiled (Goldstone et al., 2006; Krishnamurthy et al., 2006). For wound-healing genes, we identified conserved domains in the query proteins using the conserved domain search function at Pfam (Fig. 2b). We then identified all Nematostella proteins that contained one of these conserved Pfam domains (Finn et al., 2006) by searching a database of predicted proteins at StellaBase 1.0 (Sullivan et al., 2008) using a Hidden Markoff Model search algorithm (Fig. 2c; Durbin et al., 1998). Nematostella proteins were scored as possessing a particular Pfam domain if the match to a query sequence received an Expect value $\leq$ $1 \mathrm{e}-6$. These proteins predicted by using StellaBase were then cross-referenced with predicted Nematostella proteins at NCBI using BLASTp (Fig. 2d). Since this search identifies all proteins matching a particular domain, even those that are not implicated in stress response, the proteins identified in our search were compared against the human Ref Seq database (downloaded 1 Oct. 2007, containing 24306 proteins) using BLASTp to determine whether a known stress-response gene is the best match (Fig. 2e-f).

In cases where no discernible Pfam domain could be located or where only certain members of large gene families are involved in stress response, human homologs of the query sequences were identified in the non-redundant database at NCBI (Fig. 2g-h) and compared against StellaBase using BLASTp (Fig. 2i), again specifying an Expect value cut-off of e -6 to identify putative Nematostella homologs. These StellaBase-predicted proteins were then cross-referenced with predicted Nematostella proteins at NCBI using BLASTp (Fig. 2j). Each Nematostella protein identified as a best match in this search was then compared against the human genome, using tBLASTn to determine whether a known stress-response gene is the best match (Fig. $2 \mathrm{k}-1$ ).

\section{Comparison of protein motifs counts across seven species}

We used the Genome Comparison tool in StellaBase to compare the occurrence of each conserved Pfam motif in the sequenced genomes of seven different taxa. The taxa compared were Escherichia coli, Arabidopsis thaliana, Saccharomyces cerevisiae, Nematostella vectensis, Caenorhabditis elegans, Drosophila melanogaster, and Homo sapiens. Using the Pfam database (release 17), we identified Pfam domains in each genome by using a hidden Markov model

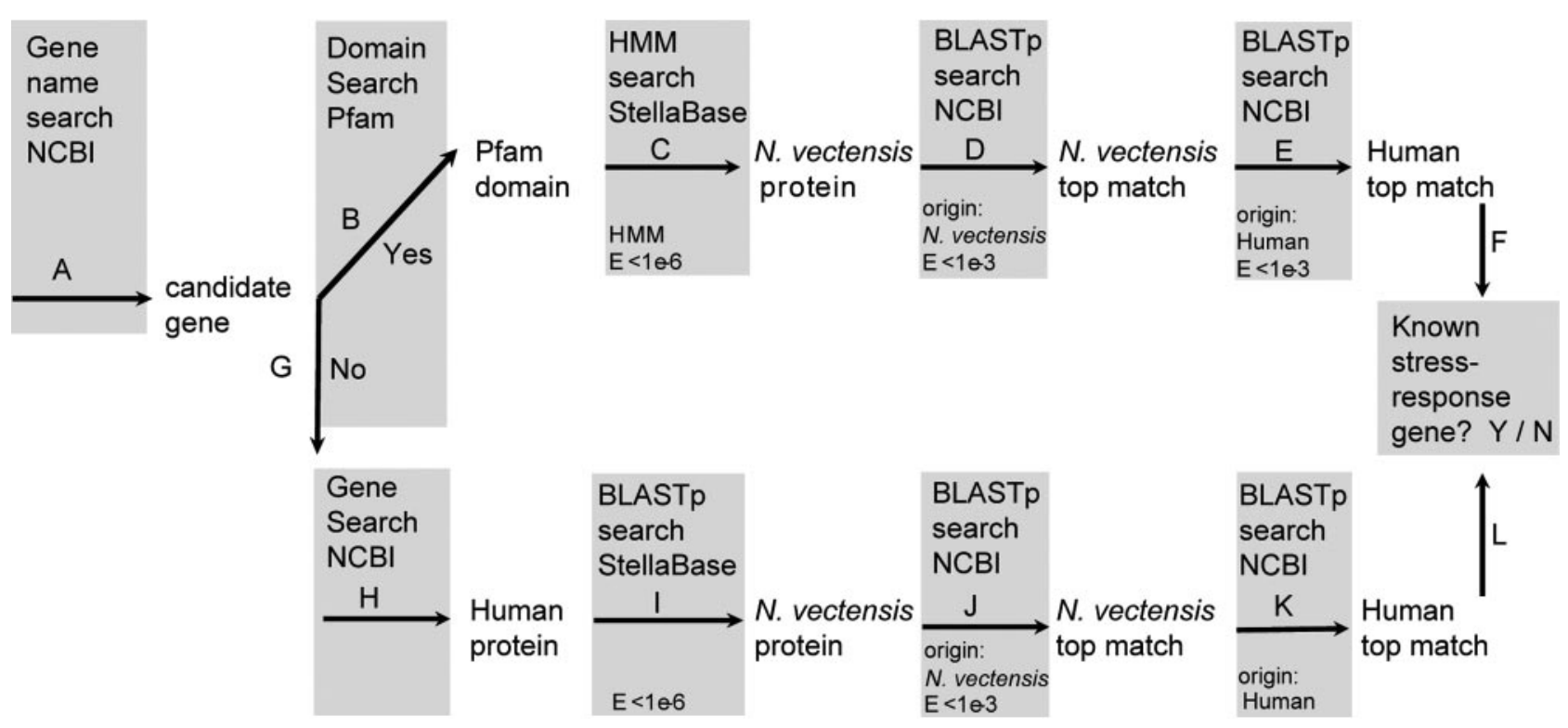

Figure 2. Workflow for identifying stress-response proteins in Nematostella, based on Pfam domain searches and BLAST similarity. 
search algorithm on the NCBI dataset for each of these species. For these searches, we queried all Pfam motifs for which we recovered at least one matching Nematostella protein. When we tallied the results across species, we included all proteins that matched a Pfam motif at an Expect value cut-off of 1e -6 (Suppl. Table 1; http://www.biolbull. org/supplemental/). To facilitate comparisons among taxa, we calculated the ratio of the number of each Pfam motif found in each taxon divided by the number found in human (Fig. 3).

\section{Results}

Overall, we screened the Nematostella genome with 137 different Pfam motifs that are known to be associated with stress-response genes in other taxa. We identified over 2400 Nematostella proteins that were significant matches to 123 different Pfam motifs (Suppl. Table 1; http://www.biolbull. org/supplemental/). Below, we discuss individual stressresponse proteins that we identified or failed to identify, categorized according to the type of stressor.

\section{Chemical stress response}

The chemical stressors that impact biodiversity in aquatic ecosystems include a diverse array of naturally and anthropogenically produced compounds (Goldstone et al., 2006). Naturally produced chemical compounds, generated by organisms or by solar radiation, include reactive oxygen species, phytotoxins, and microbial metabolites. Anthropogenic chemical insults include toxic pollutants such as heavy metals, polychlorinated biphenyls (PCBs), pesticides, herbicides, pharmaceuticals, polycyclic aromatic hydrocarbons, flame retardants (polybrominated diphenyl ethers),

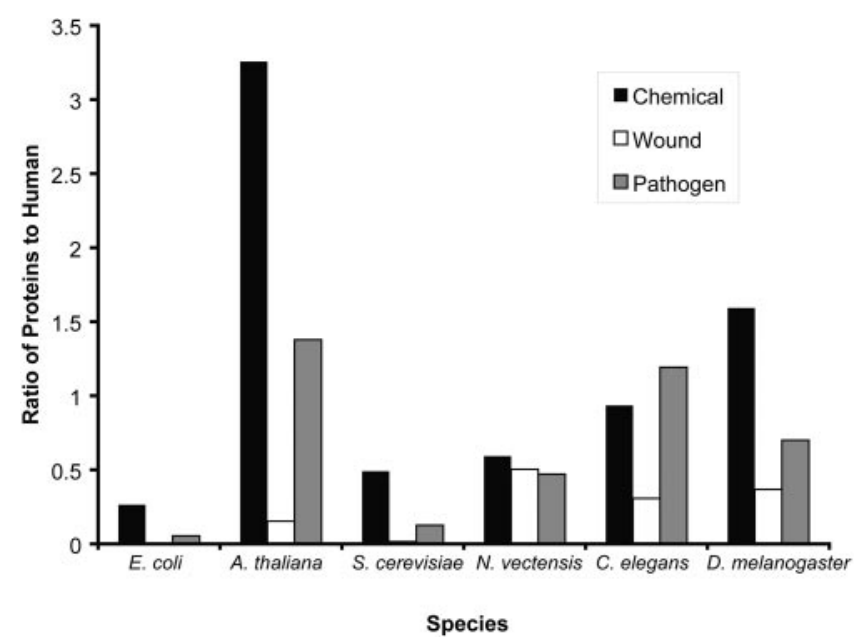

Figure 3. Comparison of the abundance of Pfam motifs associated with responses to chemical stressors, wound, and pathogens in seven model systems. Bars depict the ratio of motifs recovered from each model system relative to the number recovered from human. and organochlorine compounds (DDT, endosulfan). Estuaries are particularly susceptible to anthropogenic chemical contaminants since they are often located in the vicinity of dense coastal population centers, and their freshwater inputs tend to concentrate runoff and point sources of pollution from upstream sources. At the same time, chemical stressors generated by organisms or by solar radiation can often achieve extremely high levels in shallow estuarine pools that are only infrequently flushed by the tides.

The combination of natural and anthropogenic chemical stressors can have considerable consequences for the biodiversity in estuaries (Pennings and Bertness, 2001; Weis et al., 2004, 2005). Two biotic metrics that reveal much about the health of estuarine ecosystems are (1) the community composition - in particular, the presence and abundance of key indicator species, and (2) the physiological status of resident organisms. Increasingly, molecular and genomic methods are being employed to assay both the community composition of estuaries, particularly the microbial communities, and the physiological status of resident organisms. For example, gene expression assays have recently been employed to characterize the chemical stress response of Fundulus heteroclitus, the mummichog, an estuarine fish (Meyer et al., 2005; Schulte, 2007). The mummichog is a highly mobile animal, living in the surface waters of estuarine pools and creeks. It can migrate extensively throughout an estuary to avoid locally unfavorable conditions. However, many animals commonly found in estuaries are sessile, benthic species with limited ability to escape locally stressful conditions. Due to their lack of mobility and their habit of living in or on sediments that tend to accumulate toxicants, the gene expression profiles of such species (e.g., Nematostella) are likely to more accurately reflect the recent history of chemical stressors at a particular geographic locale.

Nematostella is an ideal estuarine sentinel species for genomic studies on chemical stress. As a sessile benthic animal and a basal metazoan, it can provide results to complement the ongoing work on Fundulus, a motile vertebrate. It is an easily collected and common inhabitant of estuaries all along the east coast of North America from Nova Scotia to Georgia and along the Gulf coast. Introduced populations can also be found in England and on the Pacific coast of North America, from central California to British Columbia (Reitzel et al., 2008). It occupies both pristine and highly contaminated habitats. For example, Nematostella has been collected in the Hackensack Meadowlands, a restored marsh located along the Hackensack River in northeastern New Jersey. This well-studied site is known to be contaminated with heavy metals (Weis et al., 2004, 2005; Barrett and McBrien, 2007), chlorinated hydrocarbons (Bopp et al., 1998), and pesticides (Barrett and McBrien, 2007).

As Nematostella's apparently low dispersal ability probably renders it unable to escape toxic contamination in the 
sediment through migration, it is likely that some populations have evolved greater tolerance to some chemical contaminants. Population genetic surveys conducted throughout the animal's extensive range have identified sharp genetic breaks between neighboring estuaries, and even between adjacent pools within single estuaries (Darling et al., 2004; Reitzel et al., 2008). Although the swimming larva represents a potential dispersal vehicle, these genetic studies suggest that the effective dispersal potential for this animal may be quite low. We have observed that larvae in culture exhibit positive geotaxis, a behavioral tendency that would contribute to their apparently limited dispersal (Reitzel, Darling, Sullivan, and Finnerty, unpubl. data).

Goldstone et al. (2006) characterized the chemical "defensome" of the sea urchin. Their classification, which we follow here, included (1) stress-activated receptors, signal transduction proteins, and transcription factors; (2) efflux pumps; (3) oxidizing enzymes; (4) reducing and conjugating enzymes; (5) antioxidant proteins; (6) metal detoxicants; and (7) heat-shock proteins. The first stage in chemical defense is environmental sensing, which involves two principal groups of genes, the PAS (Per-ARNT-SIM) family of transcription factors that respond to oxygen and small molecules, and the nuclear receptor superfamily that bind a variety of ligands, some involved in stress. Both these classes of genes regulate transcription of a variety of effector genes including cytochrome p450s (CYPs), conjugating enzymes, and transporters. Some chemical compounds that breech the cell membrane are removed by efflux proteins such as the ATP Binding Cassette (ABC) and other ion transporters such as the organic anion and cation transporters (OAT and OCT, respectively). Other chemical stressors are biotransformed to inactivate and eliminate them. Biotransformation involves two phases: oxidation, then reduction or conjugation. Oxidation is typically carried out by two families of genes, the flavoprotein monooxygenases (FMO) and the CYPs. After oxidation, compounds are reduced or conjugated by a large suite of gene families including glutathione- $S$-transferases (GSTs), sulfotransferases (SULTs), and aldo-keto reductases (AKRs). The final group of genes in chemical defense summarized by Goldstone et al. (2006) is antioxidant defenses. Reactive oxygen species (ROS), including superoxide, $\mathrm{H}_{2} \mathrm{O}_{2}$, and hydroxyl radical, are a product of both metabolism and exogenous processes (pollutants, ultraviolet radiation, hypoxia). Regardless of their source, ROS affect signal transduction cascades, transcription factors, DNA integrity, and lipids, to name a few, resulting in effects on differentiation, apoptosis, stress-responsive genes, and aging (Adler et al., 1999). A variety of antioxidant proteins including superoxide dismutase (SOD), catalases (CATs), and peroxidases have been identified in diverse metazoans that regulate ROS in the cell.
Stress-activated receptors, signal transduction pathways, and transcription factors

Nematostella possesses a number of receptor and transduction genes involved in chemical defense in sea urchin and human (Table 1). For example, a recent phylogenetic study revealed that most of the gene families in the basic helix-loop-helix (bHLH) superfamily had evolved prior to the cnidarian-triploblast divergence. Nematostella was found to possess 68 genes representing 29-32 families, including two proteins that also possess a second domain, the Per-Arnt-Sim, or PAS, domain: (1) the hypoxia inducible factor $1 \alpha$ (HIF-1 $\alpha$ ) and (2) the aryl hydrocarbon receptor nuclear translocator (ARNT; Simionato et al., 2007). In our search of the Nematostella genome, we identified three PAS proteins-ARNT, HIF- $1 \alpha$, and the aryl-hydrocarbon receptor (AHR). AHR was not identified in the earlier study, and given its presence in Hydra, its apparent absence in Nematostella was ascribed to a lineage-specific loss in the sea anemone (Simionato et al., 2007). The putative AHR homolog we identified (SB_ 56923; gil156394392), whose expression has been confirmed through an expressed sequence tag (EST) (JGI_CAGN20098.fwd), was not represented in the bHLH proteins culled from Nematostella in this previous study. However, a single "AHR related" gene, presumably the same protein, was identified in the publication of the Nematostella genome (Putnam et al., 2007). Both AHR and HIF- $1 \alpha$ form complexes with ARNT and then regulate transcription of downstream targets through recognition of xenobiotic-responsive elements (XREs) or hypoxia-responsive elements (HREs), respectively. Further bioinformatic searches for these elements in upstream re-

Table 1

Xenobiotic receptors and conditional transcription factors in Nematostella genome

\begin{tabular}{|c|c|c|c|c|}
\hline Gene Family & Gene name & $\begin{array}{c}\text { Nematostella } \\
\text { homolog }\end{array}$ & $\begin{array}{l}\text { Human gene } \\
\text { ID }\end{array}$ & $\begin{array}{r}E \\
\text { valu }\end{array}$ \\
\hline \multirow[t]{3}{*}{ bHLH-PAS } & $A H R$ & SB_50387 & gi|4502003 & $e-33$ \\
\hline & $A R N T$ & SB_15721 & gi|2702319 & e-35 \\
\hline & $H i f-1 \alpha$ & SB_27525 & gi $\mid 4504385$ & $e-32$ \\
\hline \multirow[t]{4}{*}{ CNC-bZIP \& related } & Cnc/NEF2 & SB_56664 & gi|5453774 & $e-7$ \\
\hline & Keap & SB_8385 & gi 32425813 & $e-53$ \\
\hline & Maf & SB_34218 & gi|3068761 & e- \\
\hline & & SB_16005 & & e-12 \\
\hline \multirow[t]{2}{*}{ Nuclear receptors } & Hnf4 & SB_4250 & gi|31077207 & $e-34$ \\
\hline & $R x r$ & SB_14472 & gi|5902068 & e-58 \\
\hline \multirow{4}{*}{$\begin{array}{l}\text { Metal \& heat } \\
\text { response }\end{array}$} & & & & \\
\hline & $M t f$ & SB_8762 & gi|112790163 & $e-65$ \\
\hline & $H s f$ & SB_766 & gi|5031767 & $e-45$ \\
\hline & & SB_49214 & & \\
\hline
\end{tabular}


gions of potential effector genes would provide a fruitful avenue of research in constructing gene networks.

Our search recovered likely homologs to the bZIP transcription factors NF-E2 and Maf, which heterodimerize and activate gene expression in response to oxidative and xenobiotic stress. Both were recently identified in a number of cnidarians including Nematostella (Amoutzias et al., 2007). We also identified a KEAP1, an oxidative stress and electrophile sensor protein that binds NF-E2 in the cytoplasm, preventing NF-E2 translocation to the nucleus when the cell is not under stress (Jaiswal, 2004).

Predicted Nematostella proteins also exhibit strong matches to the metal-responsive transcription factor (MTF1) and the heat-shock factor HSF1. Because each of these transcription factors regulates gene expression by binding to well-characterized recognition motifs in target genes-metal-responsive elements for MTF: TGCRCNC (Saydam et al., 2001; Zhang et al., 2001); heat-shock elements for HSF: repeats of AGAAN and its complement recognized by trimers of HSF1 (Orosz et al., 1996) -it will be possible to screen the Nematostella genome for candidate target genes.

Nematostella, like other cnidarians surveyed (Grasso et al., 2001; Thornton, 2003; Bertrand et al., 2004), lacks many of the nuclear receptors traditionally studied in organismal stress (e.g., estrogen receptors, NR1 family). However, the receptors most relevant to environmental perturbation, hepatocyte nuclear factor 4 (Hnf4) and the retinoid $\mathrm{X}$ receptor (RXR), both members of the ancestral nuclear receptor subfamily 2, appear to be present in Nematostella (Reitzel and Tarrant, unpubl. data) and other cnidarians (e.g., Grasso et al., 2001). The functional role of these genes awaits further study, but some evidence suggests that cnidarians may be susceptible to a condition resembling endocrine disruption (Tarrant, 2005). Furthermore, understand- ing the interaction of nuclear receptors and other genes involved in endocrine-like function in Nematostella may reveal how the endocrine system evolved (Tarrant, 2007).

\section{Efflux pumps}

ATP-binding cassette $(\mathrm{ABC})$ superfamily proteins are efflux transporters that pump compounds across cellular membranes against their concentration gradient (Dean and Annilo, 2005). ABC transporters are grouped into eight subfamilies (A-H) of which $\mathrm{B}, \mathrm{C}$, and $\mathrm{G}$ are known to expel toxic substances (Goldstone et al., 2006). Our search recovered 42 candidate $\mathrm{ABC}$ transporters. The $\mathrm{ABC}$ transporter complement from Nematostella is similar to that of human $(n=48)$, greater than Ciona $(n=31)$, and less than urchin $(n=65)$. Phylogenetic studies of these genes are ongoing and will allow a comparison of the $\mathrm{ABC}$ gene distribution in each subfamily.

Nematostella also has strong matches to other toxicant efflux proteins involved in removal of herbicides and toxic metals such as mercury and cadmium. We observed significant matches to the organic anion transporter polypeptide (OATP) family ( $n=4$, SB_12293, 7514, 12005, and 47307), the organic cation transporter (OCT) family $(n=1$, SB_18740), and zinc transporters $\left(n=4, \mathrm{SB} \_34021,4313\right.$, 28001, and 34688).

\section{Oxidative biotransformation}

Nematostella has putative homologs for all but one of the gene families involved in oxidative biotransformation (Table 2). The Nematostella genome encodes 48 predicted cytochrome p450s (Table 2, Supp. Table 1; http://www. biolbull.org/supplemental/), a gene family involved in oxidation of xenobiotic compounds including polycyclic aromatic hydrocarbons. Two other enzymes involved in

Table 2

Comparison of the number of proteins in the Nematostella, urchin (Strongylocentrotus purpuratus), and human genomes that exhibit significant matches to Pfam domains found in biotransformative genes

\begin{tabular}{|c|c|c|c|c|c|c|}
\hline Classification & Description & Pfam accession & Version & Nematostella & Urchin* & Human* \\
\hline \multirow[t]{4}{*}{ Oxidative } & CYP & PF00067 & 11 & 48 & 120 & 57 \\
\hline & FMO & PF00743 & 8 & 2 & 16 & 6 \\
\hline & ALDH & PF00171 & 10 & 13 & 20 & 19 \\
\hline & PTGS/COX & PF01124 & 7 & 0 & 0 & 2 \\
\hline \multirow[t]{5}{*}{ Conjugative } & GST & PF00043/02798 & $5 / 8$ & 8 & 38 & 21 \\
\hline & MGST & PF01124 & 7 & $1 \dagger$ & 12 & 3 \\
\hline & SULT & PF00685 & 14 & 5 & 36 & 13 \\
\hline & UGT & PF00201 & 8 & 1 & 49 & 13 \\
\hline & NAT & PF00797 & 7 & 0 & 1 & $2(10)$ \\
\hline \multirow[t]{2}{*}{ Reductive } & AKR-like & PF00248 & 10 & 2 & 10 & 8 \\
\hline & EPHX & PF06441 & 1 & 0 & 5 & 2 \\
\hline
\end{tabular}

\footnotetext{
* Data for urchin and human from Goldstone et al., 2006.
}

$\dagger$ A search of Nematostella expressed sequence tags using BLAST at NCBI resulted in a significant match (GI:156227921). 
oxidation of exogenous compounds-flavin-containing monooxygenase (FMO) and aldehyde dehydrogenase (ALDH) - are also present in Nematostella's genome. We did not identify a clear homolog for the prostaglandinendoperoxide synthase (PTGS/COX) in Nematostella. This result is surprising given that PTGS genes have been identified in corals (Varvas et al., 1999; Järving et al., 2004). Although the PTGS protein of the coral Gersemia fruticosa is $50 \%$ identical to the human version, the best Nematostella match is only $23 \%$ identical to human PTGS and exhibits equivalent similarity to human peroxidases. Overall, for those gene families known to be involved in oxidative biotransformation, Nematostella appears to have fewer genes than human or urchin (Table 2).

Nematostella also has a diverse set of genes involved in reductive and conjugative biotransformation. We identified Nematostella homologs for the conjugative gene families that transfer glutathione (GSTs, $n=8$ ), that metabolize xenobiotics (SULTs, $n=5$ ), and that detoxify contaminants by addition of a glycosyl group to form hydrophobic molecules (UGTs, $n=1$ ). A larger number of proteins in each of these families was detected with BLASTp searches of the Nematostella genome (footnotes in Table 2). We did not detect a Nematostella homolog of the NQO-like aldo-keto reductase superfamily or the NATs, which detoxify compounds by acetylation of amines. NQO-like AKRs have only been reported in vertebrates and appear to be a vertebrate-specific gene family (Vasiliou et al., 2006). Our Pfambased search of predicted proteins at StellaBase failed to identify a microsomal-membrane-bound glutathione transferase (MGST) or a microsomal epoxide hydrolase (EPHX). However, using BLASTp queries against the assembled Nematostella genome and ESTs produced by the Joint Genome Institute (Putnam et al., 2007), we identified one significant MGST also represented among the Nematostella ESTs (GI:156227921) and one EPHX (GI: XP_001622323). The presence of only a single MGST in Nematostella may reflect the condition found in the cnidarian-triploblast ancestor; if so, this gene family appears to have undergone a significant expansion in the Triploblastica. Overall, for the shared reductive and conjugative genes, Nematostella seems to possess fewer representatives than sea urchin or human, suggesting potential expansion after the cnidariantriploblast split (Table 2).

\section{Antioxidants and metal complexing}

The Nematostella genome appears to encode a number of proteins involved in responding to ROS, including superoxide dismutase (SOD), various peroxidases, and the glutathione pathway (Table 3). Previous research with cnidarians, primarily anthozoans, has characterized the expression of SODs and catalase (CAT) in response to environmental stress (Richier et al., 2003, 2005; Yakovleva et al., 2004; Dash et al., 2006, 2007; Merle et al., 2007).

We also identified putative homologs to the iron-storage protein ferritin, the heme-detoxification enzyme heme oxygenase 1 (HMOX1), and the metal-binding phytochelatins. Interestingly, Nematostella appears to lack any member of the evolutionarily conserved metal-binding genes, the class I and II metallothioneins, which are found in diverse eukaryotes (Hamer, 1986) including sponges (Schröder et al., 2000). Metallothioneins are also reported to be absent from Hydra (Andersen et al., 1988), suggesting that these proteins may be absent in all cnidarians. Although cnidarians seemingly lack metallothioneins, a few studies have shown that various species accumulate metals in tissue and that species exhibit differential sensitivity to particular metals

Table 3

Pfam domains found in proteins that respond to oxidative damage and metal toxicity that are represented in the Nematostella genome

\begin{tabular}{|c|c|c|c|c|c|}
\hline Classification & Pfam Name & Description & Pfam Accession & Version & Count \\
\hline \multirow[t]{6}{*}{ Oxidative damage } & Sod_Cu & Superoxide dismutase & PF00080 & 8 & 1 \\
\hline & Sob_Fe_N & Superoxide dismutase & PF00081 & 11 & 1 \\
\hline & An_peroxidase & Peroxidase & PF03098 & 5 & 4 \\
\hline & Catalase & Catalase & PF00199 & 8 & $1^{1}$ \\
\hline & GSHPx & Glutathione peroxidase & PF00255 & 9 & 6 \\
\hline & Thioredoxin & Thioredoxin & PF00085 & 8 & 13 \\
\hline \multirow[t]{6}{*}{ Metal complexing } & Metallothio & Metallothionein & PF00131 & 8 & 0 \\
\hline & Cu-oxidase & Multicopper oxidase & PF00394 & 11 & 1 \\
\hline & Transferrin & Transferrin & PF00405 & 7 & 1 \\
\hline & Ferritin & Ferritin & PF00210 & 11 & 1 \\
\hline & Heme_oxygenase & Heme_oxygenase & PF01126 & 10 & 1 \\
\hline & Phytochelatin & Phytochelatin synthase & PF05023 & 4 & 2 \\
\hline \multirow[t]{3}{*}{ Glutathione cycling } & GCS & Glutamate cysteine ligase & PF03074 & 5 & 1 \\
\hline & GSH_synthase & Eukaryotic glutathione synthase & PF03199 & 5 & 1 \\
\hline & Glutaredoxin & Glutathione reductase & PF00462 & 10 & 4 \\
\hline
\end{tabular}

\footnotetext{
${ }^{1}$ Significant BLAST match to Nematostella predicted protein in GenBank (GI: 156386091).
} 
(Karntanut and Pascoe, 2000, 2002, 2007; Mitchelmore et al., 2003a). Studies on the anemone Anthopleura elegantissima have suggested that the accumulation of metals may be influenced by glutathione, a metal-binding antioxidant, as well as by endosymbionts (Mitchelmore et al., 2003a, b). Nematostella has a number of glutathione peroxidases (Table 3), enzymes that use glutathione as a cofactor, and glutathione $S$-transferases (Table 2) that catalyze conjugation and reduction reactions with glutathione as a substrate. Nematostella is not known to harbor endosymbionts.

\section{Heat-shock proteins}

HSF, identified above, is a transcription factor that regulates expression of the heat-shock proteins (HSPs), which are involved in responses to temperature fluctuations and a wide variety of other stressors. HSPs are categorized into families on the basis of the molecular weight of the protein. Nematostella has multiple representatives in the hsp20 (7), hsp70 (6), and hsp90 (3) families. HSPs from various cnidarians have been studied in a variety of stress responses including temperature (Hayes and King, 1995; Kingsley et al., 2003; Schroth et al., 2005), coral bleaching (Downs et al., 2002), and aggression (Rossi and Snyder, 2001).

\section{Innate immunity and biological stress}

Broadly, the immune system of vertebrates with jaws can be divided into adaptive and innate immunity. Through the adaptive immune system, jawed vertebrates are capable of mounting a "learned response" against infectious agents via the generation of pathogen-specific antibodies. This complex, acquired response relies on B-cells (humoral system) and T-cells (cell-mediated systems), other lymphocytes, and an ability to model an extensive number of unique antibodies via light-chain variability of immunoglobulin proteins.

However, even in those organisms that possess an adaptive immune response, an important component of organismal health is the innate immune system. The innate immune system comprises a number of disparate host-defense mechanisms that interfere with the efficacy of infection by pathogens. The first line of defense, and an integral part of the innate immune system, is a physical barrier that impedes the entrance of infectious agents. Epithelium, mucous membranes, waxy cuticles, shells, and chitinous skeletons perform such a function in phylogenetically diverse organisms. Once an infectious agent gains access, vertebrate hosts may deploy numerous components of the innate immune system, including an inflammatory response, activation of the complement system, deployment of nonspecific macrophages and other leukocytes, production of free radicals and peroxide, and the production of antimicrobial peptides. Although such antimicrobial peptides lack the degree of specificity exhibited by immunoglobulins, they bind cell structural elements or macromolecules that are specific to major clades of infectious organisms.

A comparison of nonvertebrate deuterostomes (e.g., sea urchin) and basal vertebrates (lamprey, hagfish) reveals that the adaptive immune system is a vertebrate invention (Sodergren et al., 2006). In contrast, the evolutionary origin of the innate immune system remains obscure. Its presence in both deuterostomes (e.g., human and sea urchin) and protostomes (e.g., Drosophila sp. and Limulus polyphemus) indicates that this system originated prior to the radiation of triploblasts. We found that 63 of the 128 Pfam motifs specifically implicated in innate immune function appear to have homologs in the genome of Nematostella. These 63 Pfam motifs identify 1039 unique predicted proteins housed in StellaBase that may be involved in innate immune function (Table 4).

\section{Toll-receptor-mediated innate immunity}

The Toll-Receptor pathway is a central signaling pathway in the innate immune system. Originally identified in Drosophila, Toll receptors, and their nine vertebrate homologs, the Toll-like receptors, respond to numerous bacterial cellwall constituents and the presence of viruses by initiating a signaling cascade that culminates in the activation of the transcription factors NF- $\kappa \mathrm{B}, \mathrm{AP}-1$, and/or interferon regulatory factors. These transcription factors then upregulate the expression of effector genes required for the innate response (Armant and Fenton, 2002).

Five Toll-like domains (Pfam motif: TIR) have been identified in the Nematostella genome (Miller et al., 2007; Sullivan et al., 2007). Four of these domains are present in transmembrane proteins, suggesting a role in extracellular signaling. Three of these four transmembrane proteins are associated with two or more immunoglobulin motifs, suggesting a structure reminiscent of vertebrate interleukin receptors. The remaining transmembrane-linked TIR motif is associated with numerous leucine-rich motifs, which, when combined with phylogenetic analyses, suggests a structure conserved with true Toll- and Toll-like receptors in fly and vertebrates. The final TIR domain is not associated with a transmembrane motif, but rather with a DEATH domain, indicating that this protein may act as the first step in the intracellular signaling cascade (e.g., it may be a MyD88 homolog). Like Nematostella, Hydra magnipapillata was also found to possess predicted proteins combining Toll-like receptor domains in association with transmembrane motifs (Zheng et al., 2005).

Other key elements of the innate immune system have also been identified in Nematostella, including several members of the Toll and interleukin signaling cascades such as IRAK, TRAF, ECSIT, IKK, MKK, JNK, IKB, p38, and the transcription factors NF- $\kappa \mathrm{B}$ and AP-1 (Table 4; Miller et al., 2007; 
Table 4

Pfam domains associated with innate immunity that are present in Nematostella vectensis

\begin{tabular}{|c|c|c|c|c|}
\hline Pfam name ${ }^{1}$ & Description & Accession & Version $^{2}$ & Count $^{3}$ \\
\hline AMP-binding & AMP-binding enzyme & PF00501 & 14 & 16 \\
\hline Ank & Ankyrin repeat & PF00023 & 16 & 104 \\
\hline Asp & Eukaryotic aspartyl protease & PF00026 & 13 & 1 \\
\hline BIR & Inhibitor of Apoptosis domain & PF00653 & 10 & 3 \\
\hline ВТВ & $\mathrm{BTB} / \mathrm{POZ}$ domain & PF00651 & 18 & 42 \\
\hline bZIP_1 & bZIP transcription factor & PF00170 & 10 & 1 \\
\hline bZIP_2 & Basic region leucine zipper & PF07716 & 3 & 5 \\
\hline C_tripleX & Cysteine rich repeat & PF02363 & 8 & 1 \\
\hline CARD & Caspase recruitment domain & PF00619 & 10 & 7 \\
\hline cNMP_binding & Cyclic nucleotide-binding domain & PF00027 & 16 & 11 \\
\hline DEAD_2 & DEAD_2 & PF06733 & 5 & 1 \\
\hline Death & Death domain & PF00531 & 11 & 6 \\
\hline DSL & Delta serrate ligand & PF01414 & 8 & 9 \\
\hline Dsrm & Double-stranded RNA binding motif & PF00035 & 11 & 8 \\
\hline EGF & EGF-like domain & PF00008 & 14 & 121 \\
\hline EGF_2 & EGF-like domain & PF07974 & 1 & 44 \\
\hline EGF_CA & Calcium binding EGF domain & PF07645 & 4 & 91 \\
\hline F-box & F-box domain & PF00646 & 19 & 3 \\
\hline FYVE & FYVE zinc finger & PF01363 & 11 & 9 \\
\hline Gln-synt_C & Glutamine synthetase, catalytic domain & PF00120 & 12 & 1 \\
\hline Glyco_hydro_1 & Glycosyl hydrolase family 1 & PF00232 & 8 & 2 \\
\hline Glycolytic & Fructose-bisphosphate aldolase class-I & PF00274 & 8 & 2 \\
\hline HMG_box & HMG (high mobility group) box & PF00505 & 8 & 14 \\
\hline $\operatorname{Ig}$ & Immunoglobulin domain & PF00047 & 14 & 76 \\
\hline Ion_trans & Ion transport protein & PF00520 & 17 & 53 \\
\hline Laminin_EGF & Laminin EGF-like (Domains III and V) & PF00053 & 12 & 17 \\
\hline LEA_4 & Late embryogenesis abundant protein & PF02987 & 6 & 1 \\
\hline Lipoxygenase & Lipoxygenase & PF00305 & 7 & 2 \\
\hline LRR_1 & Leucine Rich Repeat & PF00560 & 19 & 35 \\
\hline MATH & MATH domain & PF00917 & 14 & 6 \\
\hline MMR_HSR1 & GTPase of unknown function & PF01926 & 9 & 5 \\
\hline NACHT & NACHT domain & PF05729 & 2 & 2 \\
\hline NMT & Myristoyl-CoA:protein N-myristoyltransferase, N-terminal & PF01233 & 8 & 3 \\
\hline NMT_C & Myristoyl-CoA:protein N-myristoyltransferase, C-terminal & PF02799 & 4 & 1 \\
\hline Pam 16 & Pam16 & PF03656 & 3 & 2 \\
\hline PAZ & PAZ domain & PF02170 & 10 & 1 \\
\hline Pentapeptide & Pentapeptide repeats ( 8 copies) & PF00805 & 11 & 2 \\
\hline Piwi & Piwi domain & PF02171 & 7 & 4 \\
\hline Pkinase & Protein kinase domain & PF00069 & 13 & 85 \\
\hline Pkinase_Tyr & Protein tyrosine kinase & PF07714 & 3 & 88 \\
\hline PLAT & PLAT/LH2 domain & PF01477 & 9 & 17 \\
\hline $\mathrm{PP} 2 \mathrm{C}$ & Protein phosphatase $2 \mathrm{C}$ & PF00481 & 10 & 5 \\
\hline PSI & Plexin repeat & PF01437 & 12 & 2 \\
\hline $\mathrm{RCC} 1$ & Regulator of chromosome condensation (RCC1) & PF00415 & 8 & 8 \\
\hline RdRP & RNA dependent RNA polymerase & PF05183 & 2 & 4 \\
\hline Ribonuclease_3 & RNase 3 domain & PF00636 & 12 & 2 \\
\hline SAM_1 & SAM domain (Sterile alpha motif) & PF00536 & 16 & 12 \\
\hline SAM_2 & SAM domain (Sterile alpha motif) & PF07647 & 4 & 13 \\
\hline SapB_1 & Saposin-like type B, region 1 & PF05184 & 4 & 1 \\
\hline SapB_2 & Saposin-like type B, region 2 & PF03489 & 4 & 2 \\
\hline TIR & TIR domain & PF01582 & 8 & 2 \\
\hline TPR_1 & Tetratricopeptide repeat & PF00515 & 14 & 74 \\
\hline TPR_2 & Tetratricopeptide repeat & PF07719 & 3 & 74 \\
\hline TPR_4 & Tetratricopeptide repeat & PF07721 & 2 & 2 \\
\hline Tsg 101 & Tumor susceptibility gene 101 protein (TSG101) & PF05743 & 2 & 1 \\
\hline Ubiquitin & Ubiquitin family & PF00240 & 12 & 5 \\
\hline $\mathrm{UCH}$ & Ubiquitin carboxyl-terminal hydrolase & PF00443 & 16 & 9 \\
\hline WAP & WAP-type (Whey Acidic Protein) 'four-disulfide core' & PF00095 & 10 & 3 \\
\hline WD40 & WD domain, G-beta repeat & PF00400 & 18 & 83 \\
\hline $\mathrm{zf}-\mathrm{C} 2 \mathrm{H} 2$ & Zinc finger, $\mathrm{C} 2 \mathrm{H} 2$ type & PF00096 & 14 & 111 \\
\hline $\mathrm{zf}-\mathrm{C} 3 \mathrm{HC} 4$ & Zinc finger, $\mathrm{C} 3 \mathrm{HC} 4$ type (RING finger) & PF00097 & 11 & 11 \\
\hline zf-TRAF & TRAF-type zinc finger & PF02176 & 7 & 5 \\
\hline zf-UBP & $\mathrm{Zn}$-finger in ubiquitin-hydrolases and other protein & PF02148 & 7 & 1 \\
\hline
\end{tabular}

${ }^{1}$ Pfam motifs may be retrieved by placing the accession after the following URL: http://www.sanger.ac.uk/cgi-bin/Pfam/getacc? (e.g., http://www. sanger.ac.uk/cgi-bin/Pfam/getacc?PF00501 will retrieve information for Pfam motif 'AMP-binding.'

2 'Version' refers to the version / update of the Pfam motif utilized in the hidden Markoff model search.

3 'Count' refers to the number of predicted proteins in StellaBase, ver. 1.0, which match the hidden Markoff model of each domain with an $E$-value less than or equal to $1 \mathrm{e}-6$. 
Sullivan et al., 2007). Additionally, the transcription Interferonregulatory factor, also inducible by the Toll-like signaling cascade, may have a homolog in this basal animal (SB 44157, Genbank Accession gil156396757/reflXP_001637559.1; BLASTp $E$-value versus human interferon regulatory factor 2 [gil153082752|reflNP_002 190.2] $=5 \mathrm{e}^{-40}$ ). Interestingly, although Nematostella was found to possess a complex repertoire of innate immune genes, a relatively reduced complement of innate immune genes was identified in the freshwater hydrozoan Hydra magnipapillata (Miller et al., 2007).

In cnidarians, it has been suggested that Toll-like receptors might be performing an ancestral function unrelated to innate immunity (Kanzok et al., 2004; Zheng et al., 2005). Kanzok et al. (2004) argued that animals lacking a coelom, including all diploblastic animals such as cnidarians, would not benefit from production of anti-microbial peptides-a hallmark of Toll-receptor-mediated innate immunity-because diploblasts lack an internal body compartment (namely, the coelom) into which these proteins could be secreted. For a time, this hypothesis was bolstered by an inability to recover an NF- $\kappa \mathrm{B}$ or other Rel-homology domain containing transcription factor from any basal animal.

Now that many of the components of innate immunity have been identified in cnidarians, we can begin to assess whether they are performing a role homologous to the role in triploblastic animals. If functional Toll- and Interleukinsignaling cascades are indeed present in Nematostella, downstream targets of the cascade may be conserved between cnidarians and bilaterians (e.g., canonical targets of $\mathrm{NF}-\kappa \mathrm{B})$. Homologs of known targets of NF- $\kappa \mathrm{B}$ in vertebrates have been identified in Nematostella through sequence homology (Table 4; Sullivan et al., 2007). Downstream components present in Nematostella include numerous apoptosis regulators (i.e., caspases [Eckhart et al., 2007], p53, and p63), domains associated with antimicrobial peptides, antioxidant enzymes, and a putative homolog of a complement component protein (Table 4). We are currently searching the $5^{\prime}$ regions of these putative targets to identify loci that are enriched for $\kappa \mathrm{B}$ sites, and therefore potentially regulated by NF- $\kappa \mathrm{B}$, perhaps via the Toll-signaling cascade.

\section{C3-related complement system proteins}

Among cnidarians, a homolog for the complement system protein C3 was first identified in the gorgonian Swiftia exserta (Dishaw et al., 2005). In Nematostella, a systematic search of the genome for components of the complement pathway identified a $\mathrm{C} 3$ protein in addition to integrins, suggesting that a simplified complement system may be present (Nonaka and Kimura, 2006). Such a system, however, would have to be extremely simplified relative to the complement system of vertebrates, whose complexity re- quired a number of gene and genome duplications over the course of vertebrate evolution. Interestingly, Hydra magnipapillata appears to lack a C3 protein (Miller et al., 2007), although evolutionarily related A2M-domain-containing proteins are expressed in the endoderm of Hydra with an expression pattern similar to that of a $\mathrm{C} 3$ protein of the coral Acropora millepora.

\section{Wound healing}

Along with chemical insults and infection by pathogens, physical wounding is a major source of organismal stress. Indeed, different categories of stressors interact to threaten the well-being of organisms: for example, pathogens may be introduced upon wounding, and the inability to recover from wounds may be the proximate cause of death in animals that are already stressed by chemical insults or pathogens. All animal phyla exhibit some ability to recover from wounds. In those animals where it has been studied in detail, wound healing is a complex and dynamic process that requires the interaction of many factors including cytokines, intracellular signaling pathways, transcription factors, and extracellular matrix (ECM) proteins. The extent to which the wound-healing process of "basal animals" might be homologous to the wound healing of triploblastic animals is not yet known.

We expect that some genes in the wound-healing repertoire of cnidarians may be unique to this phylum and thus identifiable only through empirical studies on cnidarians. However, as the "epithelial level of organization" exhibited by Nematostella is an extremely ancient invention that dates to the common ancestor of the Eumetazoa (if not earlier), it is likely that epithelial repair mechanisms are similarly ancient, and core elements of these pathways may be deeply conserved across animals. If so, searching for homologs of known wound-healing genes should be useful to identify candidate wound-healing genes in Nematostella.

\section{Wound healing in vertebrates}

Traditionally in vertebrate models, the process of wound healing has been broken down into three distinct but overlapping phases (Singer and Clark, 1999): (1) inflammation, (2) proliferation, and (3) matrix rebuilding and remodeling. During the inflammatory stage, the coagulation pathway is activated and platelets appear at the wound site (Kiritsy et al., 1993). Under the influence of cytokines such as plateletderived growth factor (PDGF) and transforming growth factor beta (TGF-beta), these platelets form a plug at the site of injury (Franchini and Ottaviani, 2000). This phase is characterized by the activation of neutrophils, macrophages, and mast cells, which help to remove debris and bacteria from the wound site. Simultaneously, cytokines stimulate circulating cells to express integrins, and the integrins enable these cells to interact with the ECM. The proliferative 
phase is marked by the presence of fibroblasts, which produce a number of ECM components including collagen, proteoglycans, and fibronectin. Keratinocytes proliferate and migrate out to the edge of the wound site, creating a natural defense barrier. Additional cytokines are produced from fibroblasts, keratinocytes, and macrophages, and these intercellular signaling factors help to coordinate this complicated series of events. Lastly, the ECM is remodeled by the modification of collagen fibers, which results in the contraction of the wound. Collagen reorganization appears to be a very ancient component of metazoan wound healing shared among protostomes and deuterostomes (Tettamanti et al., 2005).

\section{Wound healing in cnidarians}

In cnidarians, wound healing is often followed by regeneration, and these two processes tend to be conflated in the cnidarian literature (Henry and Hart, 2005). However, two lines of evidence reveal that wound healing and regeneration are evolutionarily and mechanistically separable processes. First, there are many animal species whose regenerative abilities are limited but whose wound-healing abilities are quite well developed-for example, if the tail of a mouse is surgically removed, the wound will heal, but the tail will not regenerate. Second, even in animals with extensive regenerative ability, such as cnidarians, wounds that do not result in the loss of a body region or structure do not necessarily trigger regeneration. In Nematostella, for example, complete bisection through the body column always results in the regeneration of a missing oral crown or a missing physa (Reitzel et al., 2007). However, incomplete bisection of the body column only rarely triggers the development of an ectopic oral crown or physa. Far more often, it triggers wound healing without regeneration. Here, we focus on wound healing and not regeneration, because the former is clearly a response to acute stress.

In cnidarians, the cellular events underlying wound healing have not been characterized at the same level of detail as in vertebrates, but at least one potential parallel has been noted. In vertebrates, the inflammatory stage is characterized by the influx of specialized cells to the wound site, including phagocytes (Gillitzer and Goebeler, 2001). Similarly, in some cnidarians, including gorgonians, scleractinian corals, and sea anemones, amoebocytes are recruited from the mesoglea to the wound site, and these cells engage in phagocytosis (Hutton and Smith, 1996; Meszaros and Bigger, 1999; Olano and Bigger, 2000; Henry and Hart, 2005; Mydlarz et al., 2006). These amoebocytes that migrate to the wound site also produce ROS (Hutton and Smith, 1996), as occurs in the circulating amoebocytes of other invertebrates (Nakamura et al., 1985; Coteur et al., 2002), suggesting that these cells are playing a role in an inflammatory response.
Identifying homologs of known wound-healing genes in Nematostella

In a first step toward determining whether the wound healing process in cnidarians is homologous to that of vertebrates, we can determine whether the same genes are involved in coordinating and regulating the process. Although a complex network of genes underlies the process of wound healing in vertebrates, none of the genes so far identified appears to be uniquely involved in wound healing. Thus, it is not possible to strictly categorize any gene as a "wound healing gene." However, we can determine which genes from the entire complement of genes active during wound healing in vertebrates are present in Nematostella, and subsequent investigations can determine whether these putative homologs are deployed in a homologous fashion during wound healing in the anemone.

The genes involved in vertebrate wound healing can be broken down into the following broad functional categories: (1) intercellular signaling molecules; (2) cell surface receptors and intracellular signaling molecules, (3) transcription factors, and (4) ECM components. On the basis of a survey of the literature, we identified 31 Pfam domains in proteins associated with wound healing, including signaling molecules, cell surface receptors, intracellular signaling factors, transcription factors, and ECM components. Every one of these Pfam domains scored a significant match to at least one predicted protein in StellaBase (Table 5, Suppl. Table 1; http://www.biolbull.org/supplemental/). Overall, the 31 domains scored significant matches to 485 different anemone proteins.

Another 26 genes involved in vertebrate wound healing could not be associated with particular Pfam domains. The human homolog for each of these genes was retrieved from NCBI and a BLAST search was conducted against predicted Nematostella genes at NCBI to identify putative homologs in the sea anemone (Table 6). These human proteins included 22 ECM components in addition to TGF-beta receptor and Jun N-terminal kinase (JNK). Most of these human genes matched one or more Nematostella sequences with an Expect value at or below the threshold of e -6, and in 10 cases, a reciprocal tBLASTn search, back against the human genome, provided evidence of genuine orthology between the human and sea anemone proteins (Table 6). Below, we discuss particular wound-healing genes that appear to have homologs in Nematostella.

\section{Intercellular signaling proteins involved in wound healing - the cytokines}

In vertebrates, cytokines function in a number of important biological processes including chemostasis and cell proliferation (Faler et al., 2006), and they play key roles during both the inflammatory and proliferative stages of wound healing. Our search of the Nematostella genome 
Table 5

Pfam domains associated with wound healing that are represented in the Nematostella genome

\begin{tabular}{|c|c|c|c|c|c|}
\hline Classification & Pfam name $^{1}$ & Pfam description & Pfam number & Count $^{2}$ & Version $^{3}$ \\
\hline \multirow[t]{21}{*}{ Extracellular matrix components } & Collagen & Collagen triple helix & PF01391 & 25 & 7 \\
\hline & Fn2 & Fibronectin type II & PF00040 & 9 & 8 \\
\hline & Fn3 & Fibronectin type III & PF00041 & 107 & 10 \\
\hline & $\mathrm{TB}$ & TB domain & PF00683 & 1 & 7 \\
\hline & glypican & glypican & PF01153 & 1 & 9 \\
\hline & Laminin_EGF & Laminin EGF-like & PF00053 & 17 & 12 \\
\hline & Laminin_G_1 & Laminin $\mathrm{G}$ domain & PF00054 & 14 & 12 \\
\hline & Laminin_G_2 & Laminin $\mathrm{G}$ domain & PF02210 & 17 & 10 \\
\hline & Laminin_B & Laminin B (Domain IV) & PF00052 & 1 & 8 \\
\hline & Laminin_N & Laminin N-terminal & PF00055 & 5 & 7 \\
\hline & NIDO & Nidogen-like & PF06119 & 1 & 2 \\
\hline & LRR_1 & Leucine Rich Repeat & PF00560 & 55 & 19 \\
\hline & LRRNT & Leucine Rich Repeat N & PF01462 & 1 & 8 \\
\hline & TSP_1 & Thrombospondin type 1 & PF00090 & 54 & 8 \\
\hline & TSP_3 & Thrombospondin type 3 & PF02412 & 6 & 7 \\
\hline & TSP_C & Thrombospondin C- & PF05735 & 4 & 1 \\
\hline & hemopexin & Hemopexin & PF00045 & 3 & 8 \\
\hline & Somatomedin_B & Somatomedin B domain & PF01033 & 3 & 7 \\
\hline & VWA & von Willebrand factor & PF00092 & 98 & 14 \\
\hline & VWC & von Willebrand factor & PF00093 & 1 & 7 \\
\hline & VWD & von Willebrand factor & PF00094 & 2 & 13 \\
\hline \multirow[t]{10}{*}{ Signaling molecules and receptors } & TGF_beta & Transforming growth & PF00019 & 5 & 8 \\
\hline & Activin_recp & Activin type I and II & PF01064 & 3 & 11 \\
\hline & FGF & Fibroblast growth factor & PF00167 & 3 & 8 \\
\hline & Lectin_leg_like & Legume-like lectin & PF03388 & 1 & 3 \\
\hline & Gal_lectin & Galactose binding lectin & PF02140 & 25 & 7 \\
\hline & Lectin_C & Lectin C-type domain & PF00059 & 24 & 9 \\
\hline & $\mathrm{TNF}$ & TNF (Tumor Necrosis) & PF00229 & 1 & 8 \\
\hline & Intergrin_beta & Integrin, beta chain & PF00362 & 3 & 7 \\
\hline & FG-GAP & FG-GAP repeat & PF01839 & 7 & 11 \\
\hline & Intergin_B_tail & Integrin beta tail domain & PF07965 & 2 & 7 \\
\hline \multirow[t]{3}{*}{ Transcription factors } & $\mathrm{CP} 2$ & $\mathrm{CP} 2$ domain & PF04516 & 1 & 4 \\
\hline & MH2 & MH2 domain & PF03166 & 1 & 4 \\
\hline & MH1 & MH1 domain & PF03165 & 4 & 6 \\
\hline
\end{tabular}

\footnotetext{
${ }^{1}$ Pfam motifs may be retrieved by placing the accession number after the following URL: http://www.sanger.ac.uk/cgi-bin/Pfam/getacc? (e.g., http://www.sanger.ac.uk/cgi-bin/Pfam/getacc?PF00501 will retrieve information for Pfam motif 'AMP-binding.'

2 'Count' refers to the number of predicted proteins in StellaBase, ver. 1.0, which match the hidden Markoff model of each domain with an $E$ value less than or equal to $1 \mathrm{e}-6$.

${ }^{3}$ Version' refers to the version / update of the Pfam motif utilized in the hidden Markoff model search.
}

using a "transforming growth factor beta-like" domain (PF 00019) identified five TGF-beta ligands. Two TGF-beta factors were previously reported in this species, including a GDF5-like gene and a DPP-like gene; on the basis of their developmental expression, they are thought to be involved in axial patterning (Finnerty et al., 2004). Both of these genes were found in our Pfam domain search, as well as other TGF-beta factors identified previously (Matus et al., 2006).

There are two types of TGF-beta receptors: type I and type II. In the absence of a ligand, these receptors exist as homodimers on the surface of the cell, but they typically bind to ligands as heterotetramers (Derynck and Zhang, 2003). Activation of this signaling cascade by the binding of a TGF-beta ligand to a receptor complex can result in the nuclear translocation of SMAD proteins, which can impact cell proliferation and migration. Also, the TGF-beta signaling pathway can be Smad-independent and result in the activation of MAPK pathways, some of which have a role in the Smad activation (Derynck and Zhang, 2003). In Nematostella, we identified a single TGF-beta receptor that best matches human TGB-beta receptor I.

\section{Integrins}

Integrins are a superfamily of integral membrane proteins that function in cell migration, cell-cell adhesion, cell-ECM adhesion, and signal transduction (Takada et al., 2007). In 
Table 6

Reciprocal tBLASTn searches (human vs. anemone) using human proteins implicated in wound healing as the initial query

\begin{tabular}{|c|c|c|c|c|c|c|}
\hline Human query & ID & Nematostella hit & E value & $\begin{array}{l}\text { Reciprocal } \\
\text { human hit }\end{array}$ & $E$ value & Human gene name \\
\hline \multicolumn{7}{|l|}{ Signaling } \\
\hline Integrin, alpha 8 & NM_003638 & XM_001641385 & $1 \mathrm{e}-79$ & NM_003638 & $1 \mathrm{e}-74$ & integrin, alpha 8 \\
\hline Integrin, alpha 4 & NM_000885 & XM_001641385 & $1 \mathrm{e}-74$ & NM_003638 & $1 \mathrm{e}-74$ & integrin, alpha 8 \\
\hline$T G F$-beta type I receptor & AAD02042 & XM_001622484 & $7 e-138$ & NM_004612 & $9 e-136$ & $T G F$-beta type I receptor \\
\hline$J N K 1-B 1$ & NM_139046 & XM_001637538 & $3 e-133$ & HSU35004 & $4 \mathrm{e}-131$ & $J N K 1-B 1$ \\
\hline \multicolumn{7}{|c|}{ SLRPs (small leucine-rich-repeat proteins) } \\
\hline Biglycan & AAA52287 & XM_001639122 & $9 \mathrm{e}-17$ & AY166584 & $5 e-25$ & Vasorin \\
\hline Chondroadherin & AAK51556 & XM_001639122 & $4 e-22$ & AY166584 & $5 e-25$ & Vasorin \\
\hline Decorin & AAB60901 & XM_001633690 & 2.7 & AC104667.5 & $6 e-44$ & BAC clone RP11-810D14 \\
\hline Fibromodulin & CAA53233 & XM_001631425 & $7 e-14$ & NM_020873 & $1 \mathrm{e}-25$ & leucine rich repeat neuronal 1 \\
\hline Keratocan & NP_008966 & XM_001625510 & 0.0 & NP_002009 & 0.0 & Flightless I \\
\hline Lumican & AAA91639 & XM_001640230 & $1 \mathrm{e}-16$ & NM_017768 & $8 \mathrm{e}-34$ & leucine rich repeat cont. 40 \\
\hline Opticin & CAB53459 & XM_001623719 & $4 \mathrm{e}-08$ & NM_012293 & $6 e-32$ & peroxidasin homolog \\
\hline Osteoglycin & CAI16695 & XM_001638871 & 0.15 & AY280614 & $2 \mathrm{e}-19$ & synleurin mRNA \\
\hline PRELP & CAG47066 & XM_001630052 & $2 \mathrm{e}-15$ & NM_018214 & $3 e-43$ & leucine rich repeat cont. 1 \\
\hline \multicolumn{7}{|l|}{ Other extracellular matrix proteins } \\
\hline Agrin & CAI15575 & XM_001632399 & $3 e-75$ & NM_198576 & $1 \mathrm{e}-71$ & agrin \\
\hline Asporin & CAI16697 & XM_001638871.1 & $3 e-19$ & AY280614 & $2 \mathrm{e}-19$ & synleurin \\
\hline Dermatan Sulf. Proteoglycan & AAC50945 & XM_001623719.1 & $1 \mathrm{e}-09$ & XM_001127072 & $6 e-32$ & Peroxidasin homolog \\
\hline Dystroglycan & AAH 12740 & XM_001621519.1 & $8 \mathrm{e}-25$ & AK291692 & $5 e-21$ & similar to Dystroglycan I \\
\hline Fibromodulin & CAA51418 & XM_001629115 & $2 \mathrm{e}-15$ & BC117180 & $3 e-166$ & Leucine-rich repeat kinase 2 \\
\hline Fibronectin 1 & NM_212476 & XM_001635202.1 & $1 e-26$ & NM_019064.3 & $2 \mathrm{e}-61$ & Sidekick 2 \\
\hline Hemicentin & NP_114141.2 & XM_001625345.1 & $4 e-116$ & NM_031935 & $1 e-99$ & Hemicentin 1 \\
\hline Matrilin 1 & NP_002370 & XM_001618434 & $1 \mathrm{e}-42$ & BC131710 & $2 \mathrm{e}-40$ & Matrilin 1 \\
\hline Matrilin 2 & AAH10444 & XM_001636411 & $2 \mathrm{e}-91$ & AB209735 & $3 e-107$ & Fibrillin 2 \\
\hline Netrin 1 & NP_004813 & XM_001628849 & $3 e-158$ & NM_004822 & $4 e-160$ & Netrin 1 \\
\hline Netrin G1 & NP_055732 & XM_001628514 & $1 \mathrm{e}-145$ & BC113455 & $7 e-119$ & Laminin, beta 1 \\
\hline Osteomodulin & NP_005005 & XM_001638987 & $4 \mathrm{e}-10$ & BC128989.1 & $2 \mathrm{e}-118$ & Leucine rich repeat cont. 7 \\
\hline Osteonectin & AAA60993 & XM_001626392 & $1 \mathrm{e}-09$ & NM_003118 & $2 \mathrm{e}-08$ & Osteonectin \\
\hline Podocan & AAP79898 & XM_001631425 & $6 e-16$ & NM_130830.2 & $1 e-25$ & Leucine rich repeat cont. 15 \\
\hline Reelin & AAC51105 & XM_001635471 & $2 \mathrm{e}-04$ & NM_001410 & 0.0 & multiple EGF-like-domains 8 \\
\hline Syndecan 1 & EAX00831 & XM_001629466 & 0.24 & HSU78181 & $3 e-25$ & Human sodium channel 2 \\
\hline Syndecan 2 & NM_002998 & XM_001637329 & 1.8 & AF163151 & $1 e-22$ & Dentin sialophosphoprotein \\
\hline Syndecan 3 & NP_055469 & XM_001629466 & 1.9 & HSU78181 & $3 e-25$ & Human sodium channel 2 \\
\hline Syndecan 4 & NM_002999 & XM_001641418 & 0.12 & ВC020057 & $2 \mathrm{e}-160$ & Integrin, beta 1 \\
\hline Tenascin & CAA39628 & XM_001638256 & $6 e-64$ & XM_001133349 & 0.0 & Notch homolog 2 \\
\hline Vitronectin & EAW51082 & XM_001633180 & $1 e-13$ & ВC064803 & $7 e-62$ & matrix metallopeptidase 14 \\
\hline von Willebrand fac. & NM_000552 & XM_001636212 & $1 \mathrm{e}-118$ & XM_001130382 & $2 \mathrm{e}-152$ & similar to Mucin-5AC \\
\hline
\end{tabular}

the cell, integrins are found as heterodimers, consisting of different alpha and beta subunits. The extracellular domains of integrins interact with a variety of ligands depending on the combination of receptor units. The cytoplasmic domain can interact with signaling proteins, focal adhesions, and cytoskeletal proteins, and it is through this interaction that integrin-initiated intracellular signaling occurs (Takada et al., 2007). It has been proposed that integrins can play a role in the nuclear translocation of the transcription factor NF$\kappa \mathrm{B}$, as well as in activation of the Jun-N-terminal Protein Kinase (JNK) (Nikolopoulos et al., 2005). The JNK pathway is activated during the proliferative phase of wound healing in vertebrates and during epidermal wound repair in Drosophila (Rämet et al., 2002; Galko and Krasnow, 2004). Both alpha and beta subunits of integrins were previously cloned in the jellyfish Podocoryne carnea (Reber-Muller et al., 2001). The beta subunit has also been cloned from sponge and coral (Brower et al., 1997). A search of the Nematostella genome using the "integrin, beta chain" and "integrin beta tail domain" identifies two integrin beta loci. A tBLASTn search using human integrin alpha proteins identifies two integrin alpha loci in Nematostella.

\section{The transcription factor, grainyhead}

Grainyhead plays a role in maintaining the tension of the cuticle in Drosophila, and similarly, it is implicated in the epithelial integrity of mammals, where a mutation in this gene causes defects in wound healing and epithelial barrier formation (Uv et al., 1994; Kudryavtseva et al., 2003; Mace 
et al., 2005; Ting et al., 2005). Grainyhead can be recognized by the possession of a highly conserved CP2 domain, and this transcription factor has been identified in a wide range of triploblastic animals (Moussian and Uv, 2005). A search of the Nematostella domain using the "CP2" domain identified a single significant match. Reciprocal tBLASTn searches between the human genome and the sea anemone genome identifies this predicted protein as the Nematostella ortholog of human grainyhead.

\section{Smads}

Smads are transcription factors that are downstream of TGF-beta signaling. They are implicated in cell proliferation and migration. In general, all smads share sequence similarity in the amino-terminal and carboxy-terminal domains, MH1 and MH2 respectively (Xu, 2006). Searching the Nematostella genome for the $\mathrm{MH} 1$ and $\mathrm{MH} 2$ domains identifies four significant matches to $\mathrm{MH} 1$ and one to $\mathrm{MH} 2$. According to a BLASTp search, four of the five MH1containing proteins and the single $\mathrm{MH} 2$-containing protein are matches to human Smads. The remaining MH1-containing protein matches a human BMP.

\section{Extracellular matrix proteins important in wound healing}

During the proliferative stage of wound healing, an epithelium begins to form over the wound site, and the ECM is deposited. The ECM is a complex netting of glycoproteins, collagens, and proteoglycans. It is important for cellular remodeling during wound healing, and it is implicated in cell attachment and growth, cellular differentiation, and structural support of tissues (Huxley-Jones et al., 2007). Many ECM proteins exhibit strong evolutionary conservation across the animal kingdom. This high degree of conservation is thought to show the importance of collagenbased extracellular matrices in animals (Tettamanti et al., 2005; Aouacheria et al., 2006; Huxley-Jones et al., 2007).

\section{Collagens}

The "collagen triple helix repeat" motif was a significant match for 19 predicted proteins in the Nematostella genome. When a BLAST search was performed against the human genome, these candidate Nematostella collagens exhibited best matches to multiple human collagen genes, including alpha 1 collagens (types V, XIII, XV, XXV), an alpha 2 collagen (type $V$ ), and an alpha 5 collagen (type IV). The BLAST searches also identified matches to a human contactin 4 (also known as BIG-2) and contactin 1 associated protein. The contactins are neuronal cell adhesion molecules that belong to the immunoglobulin superfamily (Yoshihara et al., 1995).

\section{Fibronectins}

Searches using the "fibronectin type II domain" identified nine matches in the Nematostella genome, though none of these identified a fibronectin as a best match in the human genome. For example, three Nematostella hits to "fibronectin type II" were best matches to human matrix metalloproteinases (MMP-2 and MMP-9), enzymes involved in the breakdown of extracellular matrix proteins. MMP-2 and MMP-9 are unique among metalloproteinases in harboring three repeats homologous to fibronectin II (Steffensen et al., 2001). The six additional Nematostella loci that exhibit significant similarity to the "fibronectin type II" domain are best matches to human notch 2 preprotein, relaxin, vitrin, neuronal pentaxin, neuropilin, and semaphorin.

Searches using the "fibronectin type III domain" identified 101 significant matches in the Nematostella genome. Two of the genes identified are best matches to the same human fibronectin type III domain containing 3B gene, but none of the best matches are to human fibronectins. A large fraction of the Nematostella genes that were identified in the search for fibronectin type III domains are best matches to human protein tyrosine phosphatase receptors.

In an attempt to identify a bona fide fibronectin protein in Nematostella, we used tBLASTn to query the genome with the human fibronectin 1. When the best hit in the Nematostella genome was used to search the human genome, the best human match proved to be a sidekick protein (SDK2), not fibronectin 1 (Table 6).

\section{Small leucine-rich-repeat protein family}

The small leucine rich repeat proteins (SLRPs) are a family of proteoglycans that are known to play important roles in organizing structural elements in the ECM, thereby impacting cell adhesion, wound healing, and the ability to withstand mechanical stress (Matsushima et al., 2000). The proteins are grouped into four classes based on the number and type of repeats and super-repeats they possess. Class I (e.g., decorin and biglycan) and class II (e.g., fibromodulin, lumican, keratocan, and PRELP) have 12 LRRs. Class III SLRPs (e.g., opticin and osteoglycin) have 7 LRRs. Class IV consists of chondroadherin. In vertebrates, specific LRR proteins are involved in distinct extracellular matrix types. For example, biglycan and decorin (class I) act in synergy to promote skin and bone integrity in mice (Corsi et al., 2002), while the class II protein lumican plays a role in wound healing in the cornea (Kao et al., 2006).

Leucine-rich repeats are found in a wide range of proteins, including bacterial virulence factors, cell adhesion molecules, enzymes, hormone receptors, and tyrosine kinase receptors, in addition to extracellular matrix-binding glycoproteins. A search of the Nematostella genome using the "leucine-rich-repeat" domain identified 54 matching genes, but none of these genes appears to be orthologous to 
any of the vertebrate SLRPs. When the human genome was queried using these 54 anemone sequences, the top BLAST hits included a number of predicted "leucine rich repeat containing" proteins but no members of the SLRP family. Using tBLASTn, we queried the Nematostella genome with human SLRP proteins (decorin, biglycan, fibromodulin, lumican, keratocan, PRELP, opticin, osteoglycin, and chondroadherin). We then queried the human genome with the top BLAST hits from Nematostella, and not one of these reciprocal BLAST searches identified the human SLRP protein originally used to query Nematostella as the top hit. In all cases, other human LRR-containing proteins were identified (Table 6). These same SLRPs also seem to be lacking in protostome animals (Table 7), suggesting that they are deuterostome or vertebrate inventions (HuxleyJones et al., 2007). The complexity of this gene family in vertebrates may be correlated with the diversity of vertebrate ECM types (cartilage, bone, tendon, cornea, tooth, etc.)

\section{Other extracellular matrix genes}

On the basis of reciprocal tBLASTn searches (Table 6), we were able to identify Nematostella orthologs of the human ECM proteins matrilin 1, netrin 1, osteonectin, and von Willebrand factor, but not reelin, syndecan-1, syndecan-2, syndecan-3, syndecan-4, tenascin, or vitronectin. A syndecan was previously reported in Nematostella (Chakravarti and Adams, 2006). A single predicted protein in StellaBase (SB_50645) does exhibit greater resemblance to syndecan than to any other protein family represented in Pfam. However, the resemblance is weak (E-value $=0.02$ ), and it is based primarily upon similarities in the short "cytoplasmic domain 1" (C1). Within this domain, the predicted Nematostella protein (RLRKRDEGSY) is identical to human syndecans (RMK/RKKDEGSY) at 7 or 8 of 10 residues (Chakravarti and Adams, 2006). However, a tBLASTn search of human genome using the anemone protein as a query did not return any hits. This suggests that

Table 7

Reciprocal tBLASTn searches (human vs. protostome) using human genes implicated in wound healing in the initial query

\begin{tabular}{|c|c|c|c|c|c|c|}
\hline Extracellular matrix proteins & ID & Protostome hit & $E$ value & $\begin{array}{l}\text { Reciprocal } \\
\text { human hit }\end{array}$ & $E$ value & Human gene name \\
\hline \multicolumn{7}{|l|}{$\begin{array}{l}\text { Human query SLRPs (small } \\
\text { leucine-rich-repeat proteins) }\end{array}$} \\
\hline Biglycan & AAA52287 & XM_001649763 & $3 e-21$ & NM_003061 & $1 e-44$ & SLIT1 \\
\hline Chondroadherin & AAK51556 & XM_970227 & $3 e-26$ & AK125112 & $2 e-39$ & Similar to platelet glycoprotein \\
\hline Decorin & AAB60901 & No match & $\mathrm{n} / \mathrm{a}$ & $\mathrm{n} / \mathrm{a}$ & $\mathrm{n} / \mathrm{a}$ & $\mathrm{V}$ precursor $\mathrm{n} / \mathrm{a}$ \\
\hline Fibromodulin & CAA53233 & AJ549813 & $9 e-21$ & NM_018490 & $1 e-121$ & $\begin{array}{l}\text { Leucine-rich-repeat-containing } \mathrm{G} \\
\text { protein-coupled receptor } 4\end{array}$ \\
\hline Keratocan & NP_008966 & XM_001650288 & $8 e-16$ & BC101065 & $1 e-40$ & Leucine-rich-repeat cont. 15 \\
\hline Lumican & AAA91639 & XM_395331 & $3 e-17$ & ВC094737 & $9 e-31$ & Toll-like receptor 3 \\
\hline Opticin & CAB53459 & XM_001606218 & $4 e-11$ & ВС094737 & $1 e-28$ & Toll-like receptor 3 \\
\hline Osteoglycin & CAI16695 & NM_206253 & $4 \mathrm{e}-04$ & EF090903 & 0 & VPO mRNA \\
\hline PRELP & CAG47066 & XM_001360484 & $2 \mathrm{e}-15$ & BC126169 & $1 \mathrm{e}-105$ & $\begin{array}{l}\text { Leucine-rich repeats \& immunoglobulin- } \\
\text { like domains }\end{array}$ \\
\hline \multicolumn{7}{|l|}{ Other extracellular matrix proteins } \\
\hline Asporin & CAI16697 & XM_967172 & $2 \mathrm{e}-28$ & AF055585 & 0.0 & Slit2 \\
\hline Dermatan Sulf. Proteoglycan & AAC50945 & XM_001650288 & $9 \mathrm{e}-14$ & BC101065 & $1 e-40$ & Leucine-rich-repeat cont. 15 \\
\hline Fibronectin 1 & NM_212476 & XM_001601320 & $3 e-33$ & X54131 & $3 e-145$ & Prot. tyrosine phosphatase beta \\
\hline Matrilin 2 & NP_002370 & AB159149 & $2 e-26$ & EU085556 & $1 e-34$ & Collagen XXIX alpha 1 \\
\hline Netrin G1 & NP_055732 & EF384215 & $6 e-40$ & HSU75586 & $\mathbf{0}$ & Human netrin-1 \\
\hline Osteomodulin & NP_005005 & XM_001658446 & $2 \mathrm{e}-16$ & AK292182 & $3 e-27$ & $\begin{array}{l}\text { Similar to insulin-like growth factor } \\
\text { binding protein, acid labiles subunit } \\
\text { (IGFALS) }\end{array}$ \\
\hline Podocan & AAP79898 & XM_001650288 & $5 e-29$ & BC101065 & $1 e-40$ & Leucine-rich-repeat cont. 15 \\
\hline Reelin & AAC51105 & XM_320234 & $9 \mathrm{e}-04$ & AB051390 & 0 & $V S G P / F$-spondin \\
\hline Syndecan 1 & EAX00831 & XM_001361667 & 1e-06 & NM_001006946 & $1 e-10$ & Syndecan 1 \\
\hline Syndecan 2 & NM_002998 & XM_966400 & $5 e-6$ & AK130131 & $2 e-15$ & Syndecan 2 \\
\hline Syndecan 3 & NP_055469 & XM_001664162 & $5 e-3$ & NM_002998 & $3 e-25$ & Syndecan 2 (SDC2) \\
\hline Syndecan 4 & NM_002999 & XM_001361667 & $4 e-10$ & NM_001006946 & $1 e-10$ & Syndecan 1 \\
\hline Tenascin & CAA39628 & XM_310633 & $8 e-62$ & XM_945786 & $\mathbf{0}$ & Odd Oz/ten-m homolog 2 s \\
\hline Vitronectin & EAW51082 & XM_308849 & $9 e-30$ & X90925 & $1 e-78$ & Matrix metalloproteinase \\
\hline von Willebrand fac. & NM_000552 & XM_001606600 & $2 \mathrm{e}-168$ & NM_198445.2 & 0 & SCO-spondin homolog \\
\hline
\end{tabular}

Entries in bold type indicate human proteins that appear, on the basis of tBLASTn searches, to have orthologs in Nematostella. 
the $\mathrm{C} 1$ domain may have predated the cnidarian-triploblast ancestor, but the ancestral syndecan may be a triploblast invention.

To determine whether the ECM proteins apparently missing from Nematostella might be exclusive to deuterostomes or vertebrates, we used tBLASTn to search for them in protostome genomes (Table 7). We then used tBLASTn to compare the top protostome hits back against the human genome to determine whether the best match would correspond to the original human query sequence. These reciprocal tBLASTn searches produced clear evidence for protostome syndecan and tenascin, suggesting that these ECM proteins may have evolved on the triploblastic stem lineage. However, we failed to identify asporin, fibronectin, matrilin, osteomodulin, podocan, reelin, or vitronectin in any protostome animals, suggesting that these ECM proteins may have originated within the Deuterostomia.

\section{Comparison of protein counts among seven diverse species}

We compared the number of predicted proteins bearing Pfam motifs associated with chemical stress, innate immunity, or wound healing in seven diverse taxa (Fig. 3, Suppl. Table 1; http://www.biolbull.org/supplemental/). As expected, E. coli encodes the fewest proteins in all three categories. For motifs associated with chemical stress response, Saccharomyces cerevisiae, Nematostella, and Caenorhabditis elegans encode fewer proteins than human, while Drosophila melanogaster and Arabidopsis thaliana encode more. A. thaliana outnumbered human for proteins containing motifs associated with chemical stress by more than 3 to 1 due to extremely abundant representation of some Pfam motifs (e.g., $\mathrm{p} 450 \mathrm{~s}$ ), despite lacking representatives for four of the assessed motifs.

For motifs associated with wound repair, the Nematostella genome encodes more proteins than any other taxon except human ( $\sim 50 \%$ as many as human), including representatives of every motif queried. However, although $\mathrm{Ne}$ matostella harbors a large number of proteins containing motifs associated with wound healing, it actually lacks homologs for many of the vertebrate proteins specifically implicated in wound healing, including fibronectin, many ECM proteins, and SLRPs. However, all other taxa lack representatives of two or more of the Pfam motifs associated with wound-healing proteins. E. coli and S. cerevisiae contained the fewest matches for the wound-repair motifs, which is unsurprising given that they are single-celled organisms.

For pathogen response, the overall number of proteins is larger in A. thaliana and $C$. elegans than in humans. With respect to pathogen defense, Nematostella exhibits fewer hits than other metazoans, but the anemone is the only taxon to have at least one protein representing each of the Pfam motifs associated with pathogen defense. For example, human contained no matches for the PF05183 (RNA-dependent RNA polymerase), but Nematostella had four hits.

\section{General Discussion and Conclusions}

Characterizing the molecular stress-response repertoire of Nematostella can be informative at four levels: (1) comparisons to triploblastic animals and non-animal models will help us to reconstruct the early evolution of stress-response pathways; (2) comparisons to species with narrower environmental tolerances, especially closely related marine anemones, will help us to understand the genomic basis for Nematostella's hardiness and ability to survive in estuarine habitats; (3) comparisons among genetically and phenotypically distinct populations of the starlet sea anemone can reveal the microevolution of stress-response pathways; and (4) identifying molecular markers of stress will augment our ability to utilize Nematostella and other Cnidaria as environmental sentinels.

\section{Early evolution of animal stress-response pathways}

Nematostella is a member of the phylum Cnidaria, a closely related outgroup to the superphylum Triploblastica (=Bilateria: Fig. 1). The Triploblastica encompasses the vast majority of animal phyla and species, and a great deal of research has been conducted in an attempt to explain the remarkable evolutionary radiation of this group (e.g., Peterson et al., 2000). Many human developmental regulatory genes and disease-related genes have clear orthologs in Nematostella, indicating that they must have originated prior to the cnidarian-triploblast split (Putnam et al., 2007; Sullivan and Finnerty, 2007). Comparing the genomic complement of stress genes in Nematostella and Triploblastica will help illuminate the stress-response system of early animals, perhaps revealing the importance of transcriptional control, a primary difference between stress-response pathways in triploblastic animals and other eukaryotes (e.g., Roelofs et al., 2008).

\section{Evolution of stress tolerance}

Nematostella occurs over a wide range of salinities (a range of practical salinity values from 2 to 54 (Sheader et al., 1997) and temperatures $\left(-1{ }^{\circ} \mathrm{C}\right.$ to $28{ }^{\circ} \mathrm{C}$; Frank and Bleakney, 1978; Williams, 1983; Sheader et al., 1997), and its remarkable environmental tolerances appear to be recently evolved. Nematostella is the only known estuarine specialist in the family Edwardsiidae, a clade of coastal marine anemones mainly restricted to temperate and polar seas where neither temperature nor salinity vary much. By contrast, within a single estuary, Nematostella may occupy isolated high marsh pools or tidal streams that flush with 
each tide-habitats that can differ substantially in temperature, dissolved oxygen, and salinity (e.g. Smith and Able, 1994). The range of Nematostella also encompasses dramatic latitudinal variation in temperature, from Nova Scotia, where marsh waters undergo seasonal freezing, to the subtropical waters of the Gulf of Mexico (Hand and Uhlinger, 1994).

The basis for Nematostella's broad environmental tolerances is not known. It could be that Nematostella's genome encodes more stress-response genes than the genomes of related marine species do, and these loci might be expressed at different environmental thresholds. Our analysis suggests this is not the case, because the number of stress-response genes in Nematostella is comparable to or even fewer than those in other surveyed metazoans. However, as our search relied on known stress-response genes from other animals, we could have failed to identify "novel" stress-response genes that may be present in the Nematostella genome. Identification of such genes will require global analysis of gene expression in Nematostella while subjecting the animal to various stressors. Similar techniques for profiling gene expression have been employed in characterizing transcriptional responses to environmental stressors in marine animals, including other cnidarians (Edge et al., 2005; Auslander et al., 2008).

Alternatively, or in concert, Nematostella populations could harbor an unusual degree of functional polymorphism in stress-response genes. Such genetic diversity could be maintained by fluctuating selection pressures. We have begun to characterize the geographic distribution and functional significance of some evolutionarily unusual proteincoding polymorphisms that have been identified in stressresponse genes (e.g., NF- $\kappa \mathrm{B}$ and deiodinase; Sullivan, Reitzel, and Finnerty, unpubl. data).

\section{Microevolution of stress response}

Commensurate with the environmental variation it encounters, Nematostella is known to harbor extensive genetic variation (Putnam et al., 2007; Sullivan et al., 2008; Reitzel et al., 2008), evident even at fine spatial scales (Darling et al., 2004; Reitzel et al., 2007). This suggests that the natural dispersal ability of the animals may be quite limited, that local adaptation may be driving genetic differentiation, or a combination of both. At the phenotypic level, we have observed significant differences among clonal stocks in their tolerance to temperature variation and oxidative stress (unpubl. results). With the identification of numerous candidate stress-response genes, we can begin to investigate the genetic basis for Nematostella's remarkable stress tolerance.

\section{Nematostella vectensis as a sentinel species}

\section{The need for estuarine sentinel species}

While estuaries are highly variable with respect to key environmental variables, they are also extremely important to marine biodiversity and heavily threatened by increasing human encroachment. Many marine species, including commercially important fishes and crustaceans, utilize estuarine habitats during pre-adult stages, and several endangered shore birds depend upon estuaries for essential forage.

Over the past century, estuarine environments have been severely degraded by increasing human encroachment (Pennings and Bertness, 2001). Estuaries are heavily impacted by anthropogenic contaminants, including heavy metals and endocrine disruptors that are released from point sources of pollution. Estuaries have also become increasingly fragmented by extensive coastal development, some of which interrupts the natural hydrological circulation, rendering the habitat unsuitable for estuarine flora and fauna.

In addition, global climate change represents a particular threat to estuarine natives, which, like other species occupying "island" habitats, may be limited in their ability to disperse to more suitable habitat islands (Stocks and Grassle, 2003; Harley et al., 2006). Global warming will affect not only temperatures in the estuaries, but also the range of other key physiochemical variables (Harley et al., 2006). For example, increasing temperatures can indirectly alter the salinity of salt marshes by impacting the frequency and severity of storms, by melting polar ice caps and increasing sea levels, by altering ocean currents, and by increasing evaporation. The geographic range of estuarine species will respond differently depending upon their physiological tolerances and dispersal ability-some may expand, some may contract, and others will merely shift. This process will alter the membership of estuarine communities, including pathogens, which may increase the incidence of disease in many estuaries. The fate of estuarine communities may depend upon the ability of resident organisms to tolerate and adapt to this combination of physical, chemical, and biotic stressors and decreasing habitat availability. It is therefore urgent that we develop more sophisticated tools to monitor the health of estuarine ecosystems.

\section{Collateral benefits for other cnidarian sentinel species}

Data on Nematostella will inform stress-response studies on other cnidarian species occupying different habitats (Fig. 4). The phylum Cnidaria is good source of environmental sentinel species because cnidarians are practically ubiquitous in aquatic habitats, and they are easily cultured via asexual propagation. Cnidarians occupy tropical, temperate, and polar latitudes, from the sea surface to the sea floor, in deep and shallow waters, and in freshwater, estuarine, ma- 


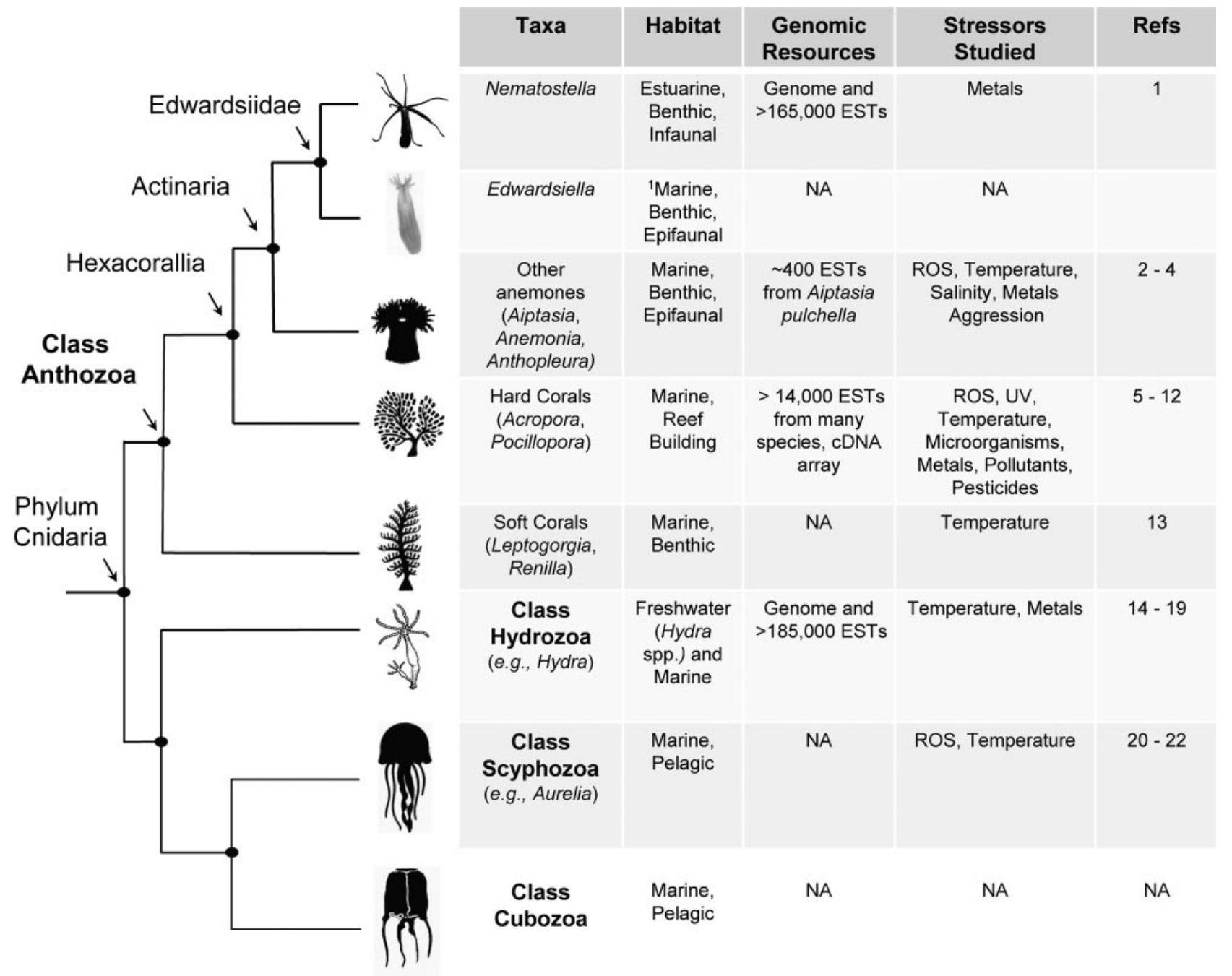

Figure 4. A selection of cnidarian model systems useful for investigating the ecological and evolutionary genomics of stress response. Most of these organisms have a coupled benthic-pelagic life history, so successive life-history stages likely encounter different stressors. Representative stress-response studies are provided for each species: 1. Harter and Matthews (2005); 2. Smith and Watt (1994); 3. Merle et al. (2007); 4. Richier et al. (2003); 5. Yakovleva et al. (2004); 6. Morgan and Snell (2002); 7. Downs et al. (2002); 8. Hayes and King (1995) 9. Jones (2005); 10. Edge et al. (2005); 11. Varvas et al. (1999); 12. Rosenberg et al. (2007); 13. Kingsley et al. (2003); 14. Bosch et al. (1988); 15. Dash et al. (2007); 16. Karntanut and Pascoe (2007); 17. Karntanut and Pascoe (2000); 18. Child (1947); 19. Dash et al. (2006); 20. (Berking et al., 2005); 21. (Schroth et al., 2005); 22. (Black and Bloom, 1984). ${ }^{1}$ Edwardsiella is benthic as an adult, but pelagic as a larva and during its parasitic phase in the ctenophore Mnemiopsis leidyi.

rine, and hypersaline environments. Their ability to reproduce asexually makes it possible to generate clonal stocks through regeneration - carefully controlled laboratory studies of organismal stress response can then eliminate genetic variation or exploit it, as desired. Repeated trials on the same genotypes (i.e., clonal lineages) exposed to the same environmental conditions can also be used to quantify stochastic variation in gene expression.

A number of cnidarian species are already being used for stress-response studies (Fig. 4), and Nematostella comple- ments these models ecologically and phylogenetically. For example, sea anemones (class Anthozoa, subclass Hexacorallia, order Actinaria) belong to the same subclass as the scleractinians, the main group of reef-building corals. Due to this relatively close evolutionary distance and the apparent similarity of coral and Nematostella genes (Miller et al., 2007), the identification of stress-response genes in the starlet sea anemone will inform ongoing genomic stressresponse research on corals, which are more limited in experimental tractability (Fig. 4). 


\section{Acknowledgments}

AMR was supported by a Postdoctoral Scholar Program at the Woods Hole Oceanographic Institution, with funding provided by The Beacon Institute for Rivers and Estuaries, and the J. Seward Johnson Fund. NTK was supported by a graduate research training grant from the National Institutes of Health. This research was also supported by NSF grant FP-91656101-0 to JCS and JRF, EPA grant F5E11155 to AMR and JRF, and a grant from the Conservation International Marine Management Area Science Program to JRF.

\section{Literature Cited}

Adler, V., Z. Yin, K. D. Tew, and Z. Ronai. 1999. Role of redox potential and reactive oxygen species in stress signaling. Oncogene 18: 6104-6111.

Alvarado, A. S., and P. A. Tsonis. 2006. Bridging the regeneration gap: genetic insights from diverse animal models. Nat. Rev. Genet. 7: 873-884.

Amoutzias, G. D., A. S. Veron, J. Weiner III, M. Robinson-Rechavi, E. Bornberg-Bauer, S. G. Oliver, et al. 2007. One billion years of bZIP transcription factor evolution: conservation and change in dimerization and DNA-binding site specificity. Mol. Biol. Evol. 24: 827835 .

Andersen, R. L., W. Wiger, H. L. Daae, and K. D. H. Eriksen. 1988. Is the metal binding protein metallothionein present in the coelenterate Hydra attenuata? J. Comp. Physiol. 91: 553-557.

Ankley, G. T., G. P. Daston, S. J. Degitz, N. D. Denslow, R. A. Hoke, S. W. Kennedy, A. L. Miracle, E. J. Perkins, J. Snape, D. E. Tillitt, et al. 2006. Toxicogenomics in regulatory ecotoxicology. Environ. Sci. Technol. 40: 4055-4065.

Aouacheria, A., C. Geourjon, N. Aghajari, V. Navratil, G. Deleage, C. Lethias, and J.-Y. Exposito. 2006. Insights into early extracellular matrix evolution: spongin short chain collagen-related proteins are homologous to basement membrane type IV collagens and form a novel family widely distributed in invertebrates. Mol. Biol. Evol. 23: $2288-2302$

Aris-Brosou, S., and Z. Yang. 2002. Effects of models of rate evolution on estimation of divergence dates with special reference to the metazoan 18S ribosomal RNA phylogeny. Syst. Biol. 51: 703-714.

Armant, M. A., and M. J. Fenton. 2002. Toll-like receptors: a family of pattern-recognition receptors in mammals. Genome Biol. 3: REVIEWS3011.

Auslander, M., Y. Yudkovski, V. Chalifa-Caspi, B. Herut, R. Ophir, R. Reinhardt, P. M. Neumann, and M. Tom. 2008. Pollution-affected fish hepatic transcriptome and its expression patterns on exposure to cadmium. Mar. Biotechnol. 10: 250-261.

Barrett, K., and M. McBrien. 2007. Chemical and biological assessment of an urban, estuarine marsh in northeastern New Jersey USA. Environ. Monit. Assess. 124: 63-88.

Berking, S., N. Czech, M. Gerharz, K. Herrmann, U. Hoffmann, H. Raifer, G. Sekul, B. Siefker, A. Sommerei, and F. Vedder. 2005. A newly discovered oxidant defence system and its involvement in the development of Aurelia aurita (Scyphozoa, Cnidaria): reactive oxygen species and elemental iodine control medusa formation. Int. J. Dev. Biol. 49: 969-976.

Bertrand, S., F. G. Brunet, H. Escriva, G. Parmentier, V. Laudet, and M. Robinson-Rechavi. 2004. Evolutionary genomics of nuclear receptors: from twenty-five ancestral genes to derived endocrine systems. Mol. Biol. Evol. 21: 1923-1937.

Black, R. E., and L. Bloom. 1984. Heat shock proteins in Aurelia (Cnidaria, Scyphozoa). J. Exp. Zool. 230: 303-307.
Bopp, R. F., S. N. Chillrud, E. L. Shuster, H. J. Simpson, and F. D. Estabrooks. 1998. Trends in chlorinated hydrocarbon levels in Hudson River basin sediments. Environ. Health Perspect. 106: 10751081.

Bosch, T. C. G., S. M. Krylow, H. R. Bode, and R. E. Steele. 1988. Thermotolerance and synthesis of heat shock proteins: These responses are present in Hydra attenuata but absent in Hydra oligactis. Proc. Natl. Acad. Sci. USA 85: 7927-7931.

Brower, D. L., S. M. Brower, D. C. Hayward, and E. E. Ball. 1997. Molecular evolution of integrins: genes encoding integrin beta subunits from a coral and a sponge. Proc. Natl. Acad. Sci. USA 94: 9182-9187.

Chakravarti, R., and J. Adams. 2006. Comparative genomics of the syndecans defines an ancestral genomic context associated with matrilins in vertebrates. BMC Genomics 7: 83.

Child, C. M. 1947. Oxidation and reduction of indicators by hydra. $J$. Exp. Zool. 104: 153-195.

Corsi, A., T. Xu, X. D. Chen, A. Boyde, J. Liang, M. Mankani, B. Sommer, R. V. Iozzo, I. Eichstetter, P. G. Robey, et al. 2002. Phenotypic effects of biglycan deficiency are linked to collagen fibril abnormalities, are synergized by decorin deficiency, and mimic EhlersDanlos-like changes in bone and other connective tissues. J. Bone Miner. Res. 17: 1180-1189.

Coteur, G., M. Warnau, M. Jangoux, and P. Dubois. 2002. Reactive oxygen species (ROS) production by amoebocytes of Asterias rubens (Echinodermata). Fish Shellfish Immun. 12: 187-200.

Darling, J. A., A. M. Reitzel, and J. R. Finnerty. 2004. Regional population structure of a widely introduced estuarine invertebrate: Nematostella vectensis Stephenson in New England. Mol. Ecol. 13: 2969-2981.

Dash, B., R. Metz, H. J. Huebner, W. Porter, and T. D. Phillips. 2006. Molecular characterization of phospholipid hydroperoxide glutathione peroxidases from Hydra vulgaris. Gene 381: 1-12.

Dash, B., R. Metz, H. J. Huebner, W. Porter, and T. D. Phillips. 2007. Molecular characterization of two superoxide dismutases from Hydra vulgaris. Gene 387: 93-108.

Dean, M., and T. Annilo. 2005. Evolution of the ATP-binding cassette $(\mathrm{ABC})$ transporter superfamily in vertebrates. Аппи. Rev. Genomics Hum. Genet. 6: 123-142.

Derynck, R., and Y. E. Zhang. 2003. Smad-dependent and Smadindependent pathways in TGF- $\beta$ family signalling. Nature 425: $577-$ 584.

Dishaw, L. J., S. L. Smith, and C. H. Bigger. 2005. Characterization of a C3-like cDNA in a coral: phylogenetic implications. Immunogenetics 57: 535-548.

Downs, C. A., J. E. Fauth, J. C. Halas, P. Dustan, J. Bemiss, and C. M. Woodley. 2002. Oxidative stress and seasonal coral bleaching. Free Radic. Biol. Med. 33: 533-543.

Durbin, R., S. Eddy, A. Krogh, and G. Mitchison. 1998. Biological Sequence Analysis: Probabilistic Models of Proteins and Nucleic Ac$i d s$. Cambridge University Press, Cambridge.

Eckhart, L., H. Fischer, and E. Tschachler. 2007. Phylogenomics of caspase-activated DNA fragmentation factor. Biochem. Biophys. Res. Comm. 356: 293-299.

Edge, S. E., M. B. Morgan, D. F. Gleason, and T. W. Snell. 2005. Development of a coral cDNA array to examine gene expression profiles in Montastraea faveolata exposed to environmental stress. Mar. Pollut. Bull. 51: 507-523.

Faler, B. J., R. A. Macsata, D. Plummer, L. Mishra, and A. N. Sidawy. 2006. Transforming growth factor- $\beta$ and wound healing. Perspect. Vasc. Surg. Endovasc. Ther. 18: 55-62.

Finn, R. D., J. Mistry, B. Schuster-Bockler, S. Griffiths-Jones, V. Hollich, T. Lassmann, S. Moxon, M. Marshall, A. Khanna, R. Durbin, et al. 2006. Pfam: clans, web tools and services. Nucleic Acids Res. 34: D247-251. 
Finnerty, J. R., K. Pang, P. Burton, D. Paulson, and M. Q. Martindale. 2004. Origins of bilateral symmetry: Hox and $d p p$ expression in a sea anemone. Science 304: 1335-1337.

Franchini, A., and E. Ottaviani. 2000. Repair of molluscan tissue injury: role of PDGF and TGF-alpha. Tissue Cell 32: 312-321.

Frank, P. G., and J. S. Bleakney. 1978. Asexual reproduction, diet, and anomalies of the anemone Nematostella vectensis in Nova Scotia. Can. Field-Nat. 92: 259-263.

Galko, M. J., and M. A. Krasnow. 2004. The molecular biology of wound healing. PLoS Biol. 2: e278.

Gillitzer, R., and M. Goebeler. 2001. Chemokines in cutaneous wound healing. J. Leukoc. Biol. 69: 513-521.

Goldstone, J. V., A. Hamdoun, B. J. Cole, M. Howard-Ashby, D. W. Nebert, M. Scally, M. Dean, E. Epel, M. E. Hahn, and J. J. Stegeman. 2006. The chemical defensome: environmental sensing and response genes in the Strongylocentrotus purpuratus genome. Dev. Biol. 300: 366-384.

Grasso, L. C., D. C. Hayward, J. W. H. Trueman, K. M. Hardie, P. A. Janssens, and E. E. Ball. 2001. The evolution of nuclear receptors: evidence from the coral Acropora. Mol. Phylogenet. Evol. 21: 93-102.

Hamer, D. H. 1986. Metallothionein. Annu. Rev. Biochem. 55: 913951.

Hand, C., and K. Uhlinger. 1994. The unique, widely distributed sea anemone, Nematostella vectensis Stephenson: a review, new facts, and questions. Estuaries 17: 501-508.

Harley, C. D. G., A. Randall Hughes, K. M. Hultgren, B. G. Miner, C. J. B. Sorte, C. S. Thornber, L. F. Rodriguez, L. Tomanek, and S. L. Williams. 2006. The impacts of climate change in coastal marine systems. Ecol. Lett, 9: 228-241.

Harter, V. L., and R. A. Matthews. 2005. Acute and chronic toxicity test methods for Nematostella vectensis Stephenson. Bull. Environ. Contam. Toxicol. 74: 830-836.

Hayes, R. L., and C. M. King. 1995 . Induction of 70-kD heat shock protein in scleractinian corals by elevated temperature: significance for coral bleaching. Mol. Mar. Biol. Biotechnol. 4: 36-42.

Henry, L., and M. W. Hart. 2005. Regeneration from injury and resource allocation in sponges and corals-a review. Int. Rev. Hydrobiol. 90: 125-158.

Hutton, D. M. C., and V. J. Smith. 1996. Antibacterial properties of isolated amoebocytes from the sea anemone Actinia equina. Biol. Bull. 191: 441-451.

Huxley-Jones, J., D. L. Robertson, and R. P. Boot-Handford. 2007. On the origins of the extracellular matrix in vertebrates. Matrix Biol. 26: $2-11$.

Jaiswal, A. K. 2004. Nrf2 signaling in coordinated activation of antioxidant gene expression. Free Radic. Biol. Med. 36: 1199-1207.

Järving, R., I. Järving, R. Kurg, A. R. Brash, and N. Samel. $2004 . \quad$ On the evolutionary origin of cyclooxygenase (COX) isozymes: Characterization of marine invertebrate Cox genes points to independent duplication events in vertebrate and invertebrate lineages. J. Biol. Chem. 279: 13624-13633.

Jones, R. 2005. The ecotoxicological effects of Photosystem II herbicides on corals. Mar. Pollut. Bull. 51: 495-506.

Kanzok, S. M., N. T. Hoa, M. Bonizzoni, C. Luna, Y. Huang, A. R. Malacrida, and L. Zheng. 2004. Origin of Toll-like receptormediated innate immunity. J. Mol. Evol. 58: 442-448.

Kao, W. W., J. L. Funderburgh, Y. Xia, C. Y. Liu, and G. W. Conrad. 2006. Focus on molecules: lumican. Exp. Eye Res. 82: 3-4.

Karntanut, W., and D. Pascoe. 2000. A comparison of methods for measuring acute toxicity to Hydra vulgaris. Chemosphere 41: 15431548.

Karntanut, W., and D. Pascoe. 2002. The toxicity of copper, cadmium and zinc to four different Hydra (Cnidaria: Hydrozoa). Chemosphere 47: $1059-1064$.
Karntanut, W., and D. Pascoe. 2007. A comparison of metal accumulation by the cnidarian Hydra vulgaris directly from water or through contaminated prey and effects upon reproduction and regeneration. Songklanakarin J. Sci. Technol. 29: 869-880.

Kingsley, R. J., E. Afif, B. C. Cox, S. Kothari, K. Kriechbaum, K. Kuchinsky, A. T. Neill, A. F. Puri, and V. M. Kish. 2003. Expression of heat shock and cold shock proteins in the gorgonian Leptogorgia virgulata. J. Exp. Zool. Comp. Exp. Biol. 296A: 98-107.

Kiritsy, C. P., A. B. Lynch, and S. E. Lynch. 1993. Role of growth factors in cutaneous wound healing: a review. Crit. Rev. Oral Biol. Med. 4: 729-760.

Krishnamurthy, N., D. Brown, D. Kirshner, and K. Sjölander. 2006. PhyloFacts: an online structural phylogenomic encyclopedia for protein functional and structural classification. Genome Biol. 7: R83.

Kudryavtseva, E. I., T. M. Sugihara, N. Wang, R. J. Lasso, J. F. Gudnason, S. M. Lipkin, and B. Andersen. 2003. Identification and characterization of Grainyhead-like epithelial transactivator (GET1), a novel mammalian Grainyhead-like factor. Dev. Dyn. 226: $604-$ 617.

Lee, C. E., and T. Mitchell-Olds. 2006. Preface to the special issue: ecological and evolutionary genomics of populations in nature. Mol. Ecol. 15: 1193-1196.

Lettieri, T. 2006. Recent applications of DNA microarray technology to toxicology and ecotoxicology. Environ. Health Perspect. 114: 4-9.

Mace, K. A., J. C. Pearson, and W. McGinnis. 2005. An epidermal barrier wound repair pathway in Drosophila is mediated by grainy head. Science 308: 381-385.

Matsushima, N., T. Ohyanagi, T. Tanaka, and R. H. Kretsinger. 2000. Super-motifs and evolution of tandem leucine-rich repeats within the small proteoglycans-biglycan, decorin, lumican, fibromodulin, PRELP, keratocan, osteoadherin, epiphycan, and osteoglycin. Proteins Struct. Funct. Genet. 38: 210-225.

Matus, D. Q., K. Pang, H. Marlow, C. W. Dunn, G. H. Thomsen, and M. Q. Martindale. 2006. Molecular evidence for deep evolutionary roots of bilaterality in animal development. Proc. Natl. Acad. Sci. USA 103: $11195-11200$.

Merle, P.-L., C. Sabourault, S. Richier, D. Allemand, and P. Furla. 2007. Catalase characterization and implication in bleaching of a symbiotic sea anemone. Free Radic. Biol. Med. 42: 236-246.

Meszaros, A., and C. Bigger. 1999. Qualitative and quantitative study of wound healing processes in the coelenterate, Plexaurella fusifera: spatial, temporal, and environmental (light attenuation) influences. J. Invertebr. Pathol. 73: 321-331.

Meyer, J. N., D. C. Volz, J. H. Freedman, and R. T. D. Giulio. 2005. Differential display of hepatic mRNA from killifish (Fundulus heteroclitus) inhabiting a Superfund estuary. Aquat. Toxicol. 73: 327-341.

Miller, D. J., G. Hemmrich, E. E. Ball, D. C. Hayward, K. Khalturin, N. Funayama, K. Agata, and T. C. G. Bosch. 2007. The innate immune repertoire in Cnidaria-ancestral complexity and stochastic gene loss. Genome Biol. 8: R59.

Mitchelmore, C. L., A. H. Ringwood, and V. M. Weis. 2003a. Differential accumulation of cadmium and changes in glutathione levels as a function of symbiotic state in the sea anemone Anthopleura elegantissima. J. Exp. Mar. Biol. Ecol. 284: 71-85.

Mitchelmore, C. L., E. A. Verde, A. H. Ringwood, and V. M. Weis. 2003b. Differential accumulation of heavy metals in the sea anemone Anthopleura elegantissima as a function of symbiotic state. Aquat. Toxicol. 64: 317-329.

Morgan, M. B., and T. W. Snell. 2002. Characterizing stress gene expression in reef-building corals exposed to the mosquitoside dibrom. Mar. Pollut. Bull. 44: 1206-1218.

Moussian, B., and A. E. Uv. 2005. An ancient control of epithelial barrier formation and wound healing. BioEssays 27: 987-990.

Mydlarz, L. D., L. E. Jones, and C. D. Harvell. $2006 . \quad$ Innate immu- 
nity, environmental drivers, and disease ecology of marine and freshwater invertebrates. Аnпи. Rev. Ecol. Evol. Syst. 37: 251-288.

Nakamura, M., K. Mori, S. Inooka, and T. Nomura. 1985. In vitro production of hydrogen peroxide by the amoebocytes of the scallop, Patinopecten yessoensis (Jay). Dev. Comp. Immunol. 9: 407-417.

Nikolopoulos, S. N., P. Blaikie, T. Yoshioka, W. Guo, C. Puri, C. Tacchetti, and F. G. Giancotti. 2005. Targeted deletion of the integrin $\beta 4$ signaling domain suppresses laminin-5-dependent nuclear entry of mitogen-activated protein kinases and NF- $\kappa \mathrm{B}$, causing defects in epidermal growth and migration. Mol. Cell. Biol. 25: 6090-6102.

Nonaka, M., and A. Kimura. 2006. Genomic view of the evolution of the complement system. Immunogenetics 58: 701-713.

Olano, C. T., and C. H. Bigger. 2000. Phagocytic activities of the gorgonian coral Swiftia exserta. J. Invertebr. Pathol. 76: 176-184.

Orosz, A., J. Wisniewski, and C. Wu. 1996. Regulation of Drosophila heat shock factor trimerization: global sequence requirements and independence of nuclear localization. Mol. Cell. Biol. 16: 7018-7030.

Pennings, S. C., and M. D. Bertness. 2001. Salt marsh communities. Pp. 289-316 in Marine Community Ecology, M. D. Bertness, S. D. Gaines, and M. Hay, eds. Sinauer Associates, Sunderland, MA

Peterson, K., R. Cameron, and E. Davidson. 2000. Bilaterian origins: significance of new experimental observations. Dev. Biol. 219: 1-17.

Peterson, K. J., and N. J. Butterfield. 2005. Origin of the Eumetazoa: testing ecological predictions of molecular clocks against the Proterozoic fossil record. Proc. Natl. Acad. Sci. USA 102: 9547-9552.

Peterson, K. J., J. B. Lyons, K. S. Nowak, C. M. Takacs, M. J. Wargo, and M. A. McPeek. 2004. Estimating metazoan divergence times with a molecular clock. Proc. Natl. Acad. Sci. USA 101: 6536-6541.

Putnam, N. H., M. Srivastava, U. Hellsten, B. Dirks, J. Chapman, A. Salamov, A. Terry, H. Shapiro, E. Lindquist, V. V. Kapitonov, et al. 2007. Sea anemone genome reveals ancestral eumetazoan gene repertoire and genomic organization. Science 317: 86-94.

Rämet, M., R. Lanot, D. Zachary, and P. Manfruelli. 2002. JNK signaling pathway is required for efficient wound healing in Drosophila. Dev. Biol. 241: 145-156.

Reber-Muller, S., R. Studer, P. Muller, N. Yanze, and V. Schmid. 2001. Integrin and talin in the jellyfish Podocoryne carnea. Cell Biol. Int. 25: 753-769.

Reitzel, A. M., P. M. Burton, C. Krone, and J. R. Finnerty. 2007. Comparison of developmental trajectories in the starlet sea anemone Nematostella vectensis: embryogenesis, regeneration, and two forms of asexual fission. Invertebr. Biology 126: 99-112.

Reitzel, A. M., J. D. Darling, J. C. Sullivan, and J. R. Finnerty. 2008. Global population genetic structure of the starlet anemone Nematostella vectensis: multiple introductions and implications for conservation poliicy. Biol. Invasions. (In press).

Richier, S., P. L. Merle, P. Furla, D. Pigozzi, F. Sola, and D. Allemand. 2003. Characterization of superoxide dismutases in anoxia- and hyperoxia-tolerant symbiotic cnidarians. Biochim. Biophys. Acta 1621: $84-91$.

Richier, S., P. Furla, A. Plantivaux, P.-L. Merle, and D. Allemand. 2005. Symbiosis-induced adaptation to oxidative stress. J. Exp. Biol. 208: $277-285$.

Roelofs, D., M. G. M. Aarts, H. Schat, and N. M. Van Straalen. 2008. Functional ecological genomics to demonstrate general and specific responses to abiotic stress. Funct. Ecol. 22: 8-18.

Rosenberg, E., O. Koren, L. Reshef, R. Efrony, and I. Zilber-Rosenberg. 2007. The role of microorganisms in coral health, disease and evolution. Nat. Rev. Microbiol. 5: 355-362.

Rossi, S., and M. J. Snyder. 2001. Competition for space among sessile marine invertebrates: changes in HSP70 expression in two Pacific cnidarians. Biol. Bull. 201: 385-393.

Saydam, N., O. Georgiev, M. Y. Nakano, U. F. Greber, and W. Schaffner. 2001. Nucleo-cytoplasmic trafficking of metal-regulatory transcription factor 1 is regulated by diverse stress signals. J. Biol. Chem. 276: 25487-25495.

Schröder, H. C., K. Shostak, V. Gamulin, M. Lacorn, A. Skorokhod, V. Kavsan, and W. E. G. Müller. 2000. Purification, cDNA cloning and expression of a cadmium-inducible cysteine-rich metallothioneinlike protein from the marine sponge Suberites domuncula. Mar. Ecol. Prog. Ser. 200: 149-157.

Schroth, W., A. Ender, and B. Schierwater. 2005. Molecular biomarkers and adaptation to environmental stress in moon jelly (Aurelia spp.) Mar. Biotechnol. (NY) 7: 449-461.

Schulte, P. M. 2007. Responses to environmental stressors in an estuarine fish: interacting stressors and the impacts of local adaptation. $J$. Therm. Biol. 32: 152-161.

Sheader, M., A. M. Suwailem, and G. A. Rowe. 1997. The anemone, Nematostella vectensis, in Britain: considerations for conservation management. Aquat. Conserv. Mar. Freshw. Ecosyst. 7: 13-25.

Simionato, E., V. Ledent, G. Richards, M. Thomas-Chollier, P. Kerner, D. Coornaert, B. M. Degnan, and M. Vervoort. 2007. Origin and diversification of the basic helix-loop-helix gene family in metazoans: insights from comparative genomics. BMC Evol. Biol. 7: 33.

Singer, A. J., and R. A. Clark. 1999. Cutaneous wound healing. N. Engl. J. Med. 341: 738-746.

Smith, B. L., and W. B. Watt. 1994. Adenylate levels and environmental stress in the sea anemone Anthopleura elegantissima. Mol. Mar. Biol. Biotechnol. 3: 261-269.

Smith, K. J., and K. W. Able. 1994. Salt-marsh tide pools as winter refuges for the mummichog, Fundulus heteroclitus, in New Jersey. Estuaries 17: 226-234.

Sodergren, E., G. M. Weinstock, E. H. Davidson, R. A. Cameron, R. A. Gibbs, R. C. Angerer, L. M. Angerer, M. I. Arnone, D. R. Burgess, R. D. Burke, et al. 2006. The genome of the sea urchin Strongylocentrotus purpuratus. Science 314: 941-952.

Steffensen, B., L. Hakkinen, and H. Larjava. 2001. Proteolytic events of wound-healing - coordinated interactions among matrix metalloproteinases (MMPs), integrins, and extracellular matrix molecules. Crit. Rev. Oral Biol. Med. 12: 373-398.

Stocks, K. I., and J. F. Grassle. 2003. Benthic macrofaunal communities in partially impounded salt marshes in Delaware: comparisons with natural marshes and responses to sediment exposure. Estuaries 26: 777-789.

Sullivan, J. C., and J. R. Finnerty. 2007. A surprising abundance of human disease genes in a simple, basal animal, the starlet sea anemone (Nematostella vectensis). Genome 50: 689-692.

Sullivan, J. C., A. M. Reitzel, and J. R. Finnerty. 2006. A high percentage of introns in human genes were present early in animal evolution: evidence from the basal metazoan Nematostella vectensis. Genome Inform. 17: 219-229.

Sullivan, J. C., D. Kalaitzidis, T. D. Gilmore, and J. R. Finnerty. 2007. Rel homology domain-containing transcription factors in the cnidarian Nematostella vectensis. Dev. Genes Evol. 217: 63-72.

Sullivan, J. C., A. M. Reitzel, and J. R. Finnerty. 2008. Upgrades to StellaBase facilitate medical and genetic studies on the starlet sea anemone, Nematostella vectensis. Nucleic Acids Res. 36: D607-D611.

Takada, Y., X. Ye, and S. Simon. 2007. The integrins. Geome Biol. 8: 215.

Tarrant, A. 2007. Hormonal signaling in cnidarians: Do we understand the pathways well enough to know whether they are being disrupted? Ecotoxicology 16: 5-13

Tarrant, A. M. 2005. Endocrine-like signaling in cnidarians: current understanding and implications for ecophysiology. Integr. Comp. Biol. 45: 201-214.

Technau, U., S. Rudd, P. Maxwell, P. M. K. Gordon, M. Saina, L. C. Grasso, D. C. Hayward, C. W. Sensen, R. Saint, et al. 2005. 
Maintenance of ancestral complexity and non-metazoan genes in two basal cnidarians. Trends Genet. 21: 633-639.

Tettamanti, G., A. Grimaldi, T. Congiu, G. Perletti, M. Raspanti, R. Valvassori, and M. de Eguileor. 2005. Collagen reorganization in leech wound healing. Biol. Cell 97: 557-568.

Thornton, J. W. 2003. Nonmammalian nuclear receptors: evolution and endocrine disruption. Pure Appl. Chem. 75: 1827-1839.

Ting, S. B., J. Caddy, N. Hislop, T. Wilanowski, A. Auden, L.-L. Zhao, S. Ellis, P. Kaur, Y. Uchida, W. M. Holleran, et al. 2005. A homolog of Drosophila grainy head is essential for epidermal integrity in mice. Science 308: 411-413.

Uv, A. E., C. R. Thompson, and S. J. Bray. 1994. The Drosophila tissue-specific factor Grainyhead contains novel DNA-binding and dimerization domains which are conserved in the human protein CP2. Mol. Cell. Biol. 14: 4020-4031.

Varvas, K., I. Järving, R. Koljak, K. Valmsen, A. R. Brash, and N. Samel. 1999. Evidence of a cyclooxygenase-related prostaglandin synthesis in coral. The allene oxide pathway is not involved in prostaglandin biosynthesis. J. Biol. Chem. 274: 9923-9929.

Vasiliou, V., D. Ross, and D. W. Nebert. 2006. Update of the NAD(P)H:quinone oxidoreductase (NQO) gene family. Hum. Genomics 2: 329-335.

Weis, J. S., J. Skurnick, and P. Weis. 2004. Studies of a contaminated brackish marsh in the Hackensack Meadowlands of Northeastern New Jersey: benthic communities and metal contamination. Mar. Pollut. Bull. 49: 1025-1035.
Weis, P., K. R. Barrett, T. Proctor, and R. F. Bopp. 2005. Studies of a contaminated brackish marsh in the Hackensack Meadowlands of northeastern New Jersey: an assessment of natural recovery. Mar. Pollut. Bull. 50: 1405-1415.

Williams, R. B. 1983. Starlet sea anemone: Nematostella vectensis Stephenson 1935. Pp. 43-46 in The IUCN Invertebrate Red Data Book. International Union for Conservation of Nature and Natural Resources, Gland, Switzerland.

Xu, L. 2006. Regulation of Smad activities. Biochim. Biophys. Acta 1759: $503-513$.

Yakovleva, I., R. Bhagooli, A. Takemura, and M. Hidaka. 2004. Differential susceptibility to oxidative stress of two scleractinian corals: antioxidant functioning of mycosporine-glycine. Comp. Biochem. Physiol. B Biochem. Mol. Biol. 139: 721-730.

Yoshihara, Y., M. Kawasaki, A. Tamada, S. Nagata, H. Kagamiyama, and K. Mori. 1995. Overlapping and differential expression of BIG-2, BIG-1, TAG-1, and F3: four members of an axon-associated cell adhesion molecule subgroup of the immunoglobulin superfamily. J. Neurobiol. 28: 51-69.

Zhang, B., D. Egli, O. Georgiev, and W. Schaffner. 2001. The Drosophila homolog of mammalian zinc finger factor MTF-1 activates transcription in response to heavy metals. Mol. Cell. Biol. 21: 45054514.

Zheng, L., L. Zhang, H. Lin, M. T. McIntosh, and A. R. Malacrida. 2005. Toll-like receptors in invertebrate innate immunity. Invertebr. Survival J. 2: 105-113. 